\title{
Household Choices in Equilibrium
}

\author{
Sumru Altug; Robert A. Miller \\ Econometrica, Vol. 58, No. 3. (May, 1990), pp. 543-570.
}

Stable URL:

http://links.jstor.org/sici?sici=0012-9682\%28199005\%2958\%3A3\%3C543\%3AHCIE\%3E2.0.CO\%3B2-B

Econometrica is currently published by The Econometric Society.

Your use of the JSTOR archive indicates your acceptance of JSTOR's Terms and Conditions of Use, available at

http://www.jstor.org/about/terms.html. JSTOR's Terms and Conditions of Use provides, in part, that unless you have obtained prior permission, you may not download an entire issue of a journal or multiple copies of articles, and you may use content in the JSTOR archive only for your personal, non-commercial use.

Please contact the publisher regarding any further use of this work. Publisher contact information may be obtained at http://www.jstor.org/journals/econosoc.html.

Each copy of any part of a JSTOR transmission must contain the same copyright notice that appears on the screen or printed page of such transmission.

The JSTOR Archive is a trusted digital repository providing for long-term preservation and access to leading academic journals and scholarly literature from around the world. The Archive is supported by libraries, scholarly societies, publishers, and foundations. It is an initiative of JSTOR, a not-for-profit organization with a mission to help the scholarly community take advantage of advances in technology. For more information regarding JSTOR, please contact support@jstor.org. 


\title{
HOUSEHOLD CHOICES IN EQUILIBRIUM
}

\author{
By Sumru Altug and Robert A. Miller ${ }^{1}$
}

\begin{abstract}
This paper is an empirical investigation of equilibrium restrictions on household consumption and labor supply. It posits, estimates, and tests a model where the equilibrium behavior of agents sometimes leads them to locate on the boundary of their respective choice sets. The key to our framework is a simple factor structure which characterizes the effects of market forces on household choices and returns to financial assets. It can be rationalized by the two assumptions that household allocations are Pareto optimal and that the labor market is competitive. If markets were complete, then the factors would represent real wages to standardized labor, prices for the future contingent claims which are ultimately realized, and the marginal utilities of wealth to households. Our empirical work estimates household preferences and tests how well this parsimonious factor structure represents panel data on married couples and time series data on asset returns. Most of our estimates are roughly comparable to those found in previous work; we find no evidence against the simple factor representation, and cannot reject the intertemporal capital asset pricing model.
\end{abstract}

KEYwORDS: Labor supply and consumption, nonseparability, complete markets, simple factor structure, panel data, asset returns data, tests of orthogonality conditions.

\section{INTRODUCTION}

THERE ARE NOW several empirical studies which summarize data on consumption, labor supply, and asset prices as outcomes of dynamic optimization problems solved by agents inhabiting abstract environments. In macroeconomics, on the one hand, time series data tracking aggregates have been used to identify, estimate, and test the representative agent paradigm, with contributions by Hall (1978), Hansen and Singleton (1982, 1984), amongst others. However, the mixed success of this paradigm has led some researchers to question the validity of assumptions about population heterogeneity required to justify aggregation, and the wisdom of ignoring corner solutions when addressing labor supply data. (See Mankiw, Rotemberg, and Summers (1985), Deaton (1987), and MaCurdy (1987), for example.)

Microeconomists have exploited individual and cohort variation in data from panels and repeated cross sections to estimate models of labor supply and

\footnotetext{
${ }^{1}$ We thank a co-editor, T. MaCurdy, and two anonymous referees for their comments. An earlier version of this paper was presented at the 1986 North American Summer Meetings of the Econometric Society at Duke University; the Conference for the Applied Econometrics of Intertemporal Choice organized by Econometrica and NORC at Chicago, October, 1986; the NSF Conference on Structural Estimation of Econometric Models: Theory, Computation and Empirical Applications at Madison, August, 1987; and seminars at Boston College, Brown University, Carnegie-Mellon University, Harvard University, V.P.I., and the Universities of Minnesota, Virginia, and Western Ontario. Altug received partial financial support for this research through a fellowship from the NBER, and Miller was partially supported by NSF Grant SES-8801631. All computations were done on the Cray 1 and Cray 2 computers through grants provided by the Minnesota Supercomputer Institute and the National Science Foundation.
} 
household consumption choices. Several such studies, including Altonji (1986), Browning, Deaton, and Irish (1985), Hotz, Kydland, and Sedlacek (1988), Heckman and Sedlacek (1985), and Shaw (1989) rejected a zero restriction on certain time dummy coefficients. The respective authors interpreted their findings as evidence against the null hypothesis that aggregate fluctuations do not affect labor supply choices. Bils (1985) and Keane, Moffitt, and Runkle (1988) also found that including directly the national unemployment rate in less structured models significantly contributes to the explanatory power of their models.

While the microeconomic models mentioned above have a straightforward interpretation under the null hypothesis of no aggregate effects, a consensus has yet to emerge on precisely how aggregate shocks should be accounted for in analyses of household data. Hayashi (1985) tackled this problem using data on consumer expectations; Hotz, Kydland, and Sedlacek (1988) assumed forecast errors are additively separable into common versus idiosyncratic components; Browning, Deaton, and Irish (1985) approximated the intertemporal arbitrage condition; the model of Heckman and Sedlacek (1985) is static.

Our paper proposes and tests another candidate solution to this problem. It is laid out in Section 2. We appeal to restrictions which hold in the competitive equilibrium of an economy with a complete set of markets. The interest rate and the wage function are stochastic in our model, and their equilibrium realizations can be estimated using two sets of time dummies, along with the parameters characterizing preferences, the marginal productivities of labor, and the marginal utilities of household wealth. The coefficients on one sequence of time dummies are interpreted as discounted prices of contingent claims which are realized along the equilibrium path; the coefficients on the other sequence represent real wage rates.

At first blush, the underlying premise that a complete set of markets exists seems incredible. Yet, failing to reject the hypothesis that consumers equate their marginal rates of substitution may only reflect an inability to capture, empirically, less parsimonious restrictions generated by incomplete markets, with a small data set. In any case, our estimation and testing strategy abstracts from institutional detail to focus on the resulting consumption and leisure allocations, and real wages. To the extent that government intervention in financial markets (through social security and unemployment insurance, for example) and private charity (such as familial relationships and religious organizations provide) move these allocations towards the Pareto frontier, the contingent claims prices we estimate may be interpreted as shadow values for a hypothetical social programming problem. Given the prominent position Pareto optimality occupies in economic theory, empirical investigations of this hypothesis can be informative about the nature of equilibrium allocations, as well as the preferences and production technology which support them.

The idea of modelling Pareto optimal allocations as an empirical phenomenon is also pursued in Scheinkman (1984), who partly motivates his survey of the theoretical literature by plotting aggregate income and consumption for different 
countries over time, to see how much consumption smoothing takes place (through international financial markets and foreign aid). No formal tests are executed however. Actually, labor economists have already exploited in estimation the parsimonious representation generated by a complete set of markets. Heckman and MaCurdy (1980, 1982) and MaCurdy (1981) implicitly acknowledge this fact by making the (stronger) assumptions that households have perfect foresight and face a constant interest rate. In addition, the results obtained from imposing the complete markets hypothesis is observationally equivalent to MaCurdy (1983), Browning, Deaton, and Irish (1985) and Altonji (1986), who approximate the asset pricing equation so they can estimate an interior first order condition for male labor supply. We conclude Section 2 by comparing their procedure with ours, and establishing this result.

Longitudinal data on continuously married couples, collected by the Panel Study of Income Dynamics (PSID), is used in conjunction with time series data on returns of financial assets to estimate and test a parameterization of the framework developed in Section 2. We investigate how well equilibrium household choices about male leisure and household food consumption explain the data on these variables, wages, and returns from stocks and bonds. The parameterization and the data, described in Section 3 and an Appendix, are comparable to previous empirical work undertaken in these fields by some of the authors cited above. It is therefore natural to ask how close our results, derived under the assumption of complete markets, are to theirs. A second question is whether the simple factor structure, characterizing a complete set of markets, adequately represents the unobservables up to shocks which are independent across households and over time. Both questions are addressed in our empirical work.

Section 3 lays out the parametric forms for the preferences and labor productivities and describes the data utilized in the empirical analysis. We consider specifications in which both exogenous and endogenous time varying components enter nonadditively with (food) consumption. These features may be justified in terms of a home production function, but they also have ramifications for the intertemporal capital asset pricing model (ICAPM) tested by Hansen and Singleton (1982, 1984), Mankiw, Rotemberg, and Summers (1985), Dunn and Singleton (1986) and Eichenbaum, Hansen, and Singleton (1987). A potential source of the rejections they found is that, as we mentioned above, the data might not satisfy conditions necessary for aggregating over a heterogenous population. Since our framework does not rely on the representative consumer paradigm, we can investigate whether imposing such conditions explains why the intertemporal capital asset pricing model fails.

Our empirical methods and results are described in Sections 4. Overall, four main findings emerge. Neither the simple factor structure nor the ICAPM is rejected by the data; the coefficient estimates and structural parameters are comparable to those found in previous studies; there is some evidence against additive separability; aggregate shocks (as transmitted through equilibrium prices) are collectively significant. 


\section{A FRAMEWORK}

\section{Uncertainty, Household Preferences, and Choices}

We analyze the following model. Suppose a finite number of (exogenously determined) households inhabit an economy which runs for a countable number of periods $t \in\{1,2, \ldots, \tau\}$, where $\tau \leqslant \infty$. A typical household $n$ is active between dates $\underline{n}$ and $\bar{n}$, where $0<\underline{n}<\bar{n} \leqslant \tau$. Uncertainty in this economy is treated as the probability space $(\Omega, F, P)$, the element $\omega \in \Omega$ signifying a particular realization of all (random) variables in this economy from 1 to $\tau$. Let the increasing sequence of $\sigma$-algebras $F_{1} \subseteq F_{2} \subseteq \cdots \subseteq F$ characterize how information accumulates over time, and denote by $E_{t}$ the expectations operator associated with $F_{t}$. We assume all information is public; thus the random variables with $t$ subscripts defined below are $F_{t}$-measurable.

Although our approach applies to many competitive environments where markets are complete, our empirical study is based on data describing consumption and labor supply choices by households. For this reason we let $c_{n t}$ stand for allocations to the $n$th household in period $t$ which, in equilibrium, invariably satisfy a first order condition with equality, and $l_{n t}$ stand for those allocations which might not. In particular, let $c_{n t}$ denote consumption by the $n$th household in period $t$; let $l_{n t}$ denote a vector of leisure for the individuals belonging to it. Suppose $l_{n t}$ has only two elements, corresponding to the leisure time of spouses within each household. Then $l_{n t}=\left(l_{1 n t}, l_{2 n t}\right)$ where $l_{i n t} \in[0,1]$ measures the proportion of time in period $t$ the $i$ th member of household $n$ spends in nonmarket activities. Here we also assume $c_{n t}$ is a single homogeneous good, but extending the analysis to deal with consumption vectors is straightforward. Households are identical up to a vector of time varying characteristics $z_{n t}$. We assume an individual's labor supply can be measured in efficiency units which depend on these time varying characteristics. Let $h_{\text {int }}$ denote the labor supply of the $i$ th member belonging to the $n$th household in period $t$ weighted by an efficiency index $\gamma_{i}\left(z_{n t}\right)$ :

$$
h_{\text {int }}=\gamma_{i}\left(z_{n t}\right)\left(1-l_{\text {int }}\right) \text {. }
$$

We assume households obey the expected utility hypothesis and have rational expectations, preferences taking the time additive form

$$
E_{0}\left[\sum_{t=\underline{n}}^{\bar{n}} \beta^{t} u\left(l_{1 n t}, l_{2 n t}, c_{n t}, z_{n t}\right)\right],
$$

where $E_{0}(\cdot)$ denotes the expectation with respect to $P$ at date 0 , the scalar $\beta \in(0,1)$ is a common subjective discount factor, and $u\left(l_{1 n t}, l_{2 n t}, c_{n t}, z_{n t}\right)$ is concave increasing in $\left(l_{1 n t}, l_{2 n t}, c_{n t}\right)$ for each $z_{n t}$.

\section{Complete Markets}

Given the efficiency units assumption embodied in (2.1), one condition which holds in all the competitive equilibria we investigate is that spot labor markets 
exist, so if $l_{\text {int }}<1$, then

$$
w_{i n t}=w_{t} \gamma_{i}\left(z_{n t}\right)
$$

where $w_{t}$ is the real wage of a standard unit of labor in period $t$.

In a competitive equilibrium with complete markets, household $n$ maximizes (2.2) at date 0 (when all trades occur) by choosing the $F_{t}$-measurable vector $\left(l_{n t}, c_{n t}\right)$ for each $t \in\{\underline{n}, \ldots, \bar{n}\}$ subject to a lifetime budget constraint. Accordingly, let $p_{t}$, a measure defined on $F_{t}$ for each $t \in\{1,2, \ldots, \tau\}$, denote prices of contingent claims to consumption in period $t$. Thus, for any set $A_{t} \in F_{t}$, the nonnegative real number $p_{t}\left(A_{t}\right)$ denotes the date 0 price of a consumption unit to be delivered on date $t$, contingent on $A_{t}$ occurring. We assume $p_{t}$ is absolutely continuous with respect to $P$ and denote by $\beta^{t} \lambda_{t}$ the Radon-Nikodym derivative of $p_{t}$ with respect to $P$. Hence $p_{t}$ admits the representation

$$
p_{t}\left(A_{t}\right)=\beta^{t} \int_{A_{t}} \lambda_{t}(\omega) P(d \omega) .
$$

Setting $A_{t}=\Omega$ for example, we see that $\beta^{t} E_{0}\left(\lambda_{t}\right)$ is the price of sure period $t$ consumption. Upon defining the exogenously determined quantity $c_{n}$ as bequests net of inheritances, and given the representation for the contingent claims prices described by equation (2.4), we assume the budget constraint for the $n$th household may be written as

$$
E_{0}\left\{\sum_{t=\underline{n}}^{\bar{n}} \beta^{t} \lambda_{t}\left[c_{n t}-\sum_{i=1}^{2}\left(1-l_{\text {int }}\right) w_{i n t}\right]\right\} \leqslant c_{n} .
$$

Let $\eta_{n}$ denote the Lagrange multiplier associated with the household budget constraint in (2.5). The first order conditions for the $n$th household with respect to its choices of leisure hours $l_{n t}$ and consumption $c_{n t}$ are

$$
\begin{aligned}
& u_{i}\left(l_{1 n t}, l_{2 n t}, c_{n t}, z_{n t}\right) \geqslant \eta_{n} \lambda_{t} w_{i n t} \quad \text { for } \quad i \in\{1,2\}, \\
& u_{3}\left(l_{1 n t}, l_{2 n t}, c_{n t}, z_{n t}\right)=\eta_{n} \lambda_{t} .
\end{aligned}
$$

Here $u_{j}\left(l_{1 n t}, l_{2 n t}, c_{n t}, z_{n t}\right)$ is the partial derivative of $u\left(l_{1 n t}, l_{2 n t}, c_{n t}, z_{n t}\right)$ with respect to the $j$ th argument for $j \in\{1,2,3\}$, and (2.6) holds with equality whenever $l_{\text {int }}<1$ for $i \in\{1,2\}$. Let $l_{n t}^{0}$ and $c_{n t}^{0}$ denote the optimal leisure and consumption plans for household $n$ in equilibrium. Conditions (2.6) and (2.7) hold with probability one, but as econometricians we only observe allocations for a particular sample point $\tilde{\omega}$. The strategy we follow in the remainder of this paper is to estimate the discount factor $\beta$, the parameters of preferences $u\left(l_{1 n t}, l_{2 n t}, c_{n t}, z_{n t}\right)$ and the efficiency indices $\gamma_{i}$ for $i \in\{1,2\}$, from observations on the realized equilibrium values of household choices, namely, observations on $l_{1 n t}^{0}(\tilde{\omega}), l_{2 n t}^{0}(\tilde{\omega})$, and $c_{n t}^{0}(\tilde{\omega})$ for different $n$ and $t$. In order to use the first-order conditions in equations (2.6) and (2.7) for this purpose, we treat the equilibrium sequence of household-specific Lagrange multipliers, $\left\{\eta_{n}\right\}_{n \in N}$, and the sequences $\left\{\lambda_{t}(\tilde{\omega})\right\}_{t \in T}$ and $\left\{w_{t}(\tilde{\omega})\right\}_{t \in T}$, which arise due to time variation in equilibrium in the contingent claims prices and real wages, as parameters too. Having pointed 
this out, however, we shall henceforth suppress the dependence on $\tilde{\omega}$ (which indicates realized states of the world) and drop the degree symbol (which indicates an equilibrium choice) to ease the notational burden.

Our strategy is similar to the approach of Heckman and MaCurdy (1980), because it accounts for the existence of corner solutions by utilizing the simplification that arises from the assumption of complete markets. Indeed, these authors made the stronger assumptions that individuals possess perfect foresight and the real interest rate, denoted $r_{0}$ say, is constant. Another way of expressing the latter assumption is to note that their work assumes the sequence of contingent claims prices satisfies the deterministic relationship $p_{t}=$ $\lambda_{0}\left(1+r_{0}\right)^{-t}$ for all $t$. Consequently, our approach may be considered as an extension of Heckman and MaCurdy's, to encompass situations where real interest rates and real wages vary (stochastically) over time, an empirical phenomenon which has been picked up by the microeconomic data analyses we mentioned in the Introduction.

\section{Incomplete Markets}

In order to highlight the role of complete markets and to compare our approach with others, we now temporarily suppose that markets are not necessarily complete, but there still exist assets $r \in R$ which households may trade each period for current consumption and leisure. To simplify the exposition, suppose $R$ is countable. Then, let $s_{r n t}$ denote the quantity of asset $r$ held by the $n$th household in period $t, q_{r t}$ its price, and $d_{r t}$ the associated dividend. In this case, household opportunities cannot be modeled with a single lifetime budget constraint. Instead, multiple budget constraints of the form

$$
\sum_{r \in R}\left[q_{r t}\left(s_{r n t}-s_{r n, t+1}\right)+d_{r t} s_{r n t}\right] \geqslant c_{n t}-\sum_{i=1}^{2}\left(1-l_{i n t}\right) w_{i n t}
$$

must be satisfied for all measurable sets of $F_{t}$ and $t \in\{\underline{n}, \ldots, \bar{n}\}$. Now the household maximizes (2.2) subject to (2.8), as well as some exogenous initial and terminal conditions which are respectively dictated by inheritances and bequests. The first order conditions with respect to $l_{n t}, c_{n t}$, and $s_{r n t}, r \in R$ (which must be met with probability one) are

$$
\begin{array}{ll}
u_{i}\left(l_{1 n t}, l_{2 n t}, c_{n t}, z_{n t}\right) \geqslant \lambda_{n t} w_{i n t} & \text { for } \quad i \in\{1,2\}, \\
u_{3}\left(l_{1 n t}, l_{2 n t}, c_{n t}, z_{n t}\right)=\lambda_{n t}, & \\
\lambda_{n t}=\beta E_{t}\left[\lambda_{n, t+1} \pi_{r t}\right] & \text { for } \quad r \in R,
\end{array}
$$

where $\beta^{t} \lambda_{n t}$ is the Radon-Nikodym derivative of the period $t$ Lagrange multiplier associated with the $n$th household's budget constraint, and $\pi_{r t}$, the real return on the $r$ th asset in time $t$, is just

$$
\pi_{r t}=\left(q_{r, t+1}+d_{r, t+1}\right) / q_{r t} \text {. }
$$

The complexity induced by relaxing the assumption of complete markets is evident from considering the space in which the Lagrange multipliers reside. 
Given complete markets, $\eta_{n}$ is simply a positive real number. Contrast this with the alternative formulation above, which posits $\bar{n}-\underline{n}$ multipliers, each one belonging to the dual of the period $t$ constraint space. If, for example, some Hilbert space contains the allocations, securities, prices, and dividends entering (2.8), then the associated Lagrange multiplier belongs to the same space. In this sense such Lagrange multipliers constitute a much richer class of functions than the constant (marginal utility of wealth) associated with a single lifetime budget constraint.

Several previous studies, including MaCurdy (1983), Browning, Deaton, and Irish (1985) and Altonji (1986), have exploited conditions like (2.9) through (2.12) to estimate and test life-cycle models of consumption and labor supply which assume interior solutions. To see how their strategy is implemented, let $\varepsilon_{r n, t+1}$ be the error from forecasting $\beta \pi_{r t} \lambda_{n, t+1} / \lambda_{n t}$ conditional on $F_{t}$, information available up to date $t$. Dividing (2.11) by $\lambda_{n t}$, it follows that

$$
1+\varepsilon_{r n, t+1}=\beta \pi_{r t} \lambda_{n, t+1} / \lambda_{n t}
$$

where $\varepsilon_{r n, t+1}$ is uncorrelated with any information available at time $t$. Now first difference the logarithm of (2.10), and then substitute out the right-hand side of the resulting expression using the logarithm of (2.13). Denoting by $\Delta$ the first difference operator, we obtain

$$
\begin{aligned}
\Delta \ln \left[u_{3}\left(l_{1 n t}, l_{2 n t}, c_{n t}, z_{n t}\right)\right] & =\Delta \ln \left(\lambda_{n t}\right) \\
& =\ln \left(1+\varepsilon_{r n t}\right)-\ln \left[\beta \pi_{r, t-1}\right] \\
& =\sum_{k=1}^{\infty}(-1)^{k+1} \varepsilon_{r n t}^{k} / k-\ln \left[\beta \pi_{r, t-1}\right] .
\end{aligned}
$$

Notice the second line in (2.14) assumes returns are always nonnegative and consequently $\varepsilon_{r n t} \geqslant-1$ (because (2.13) implies $\ln \left(1+\varepsilon_{r n t}\right)$ is not defined otherwise). The third line in (2.14) is valid only if $-1<\varepsilon_{r n t} \leqslant 1$ as well.

There are two further obstacles to deriving consistent estimates of $u_{3}\left(l_{1 n t}, l_{2 n t}, c_{n t}, z_{n t}\right)$ from equation (2.14). The first is that even if the $F_{t}$ measurable function $E_{t}\left[\ln \left(1+\varepsilon_{r n t}\right)\right]$ exists for some $r \in R$, it is computationally intractible for all but the most simple models. The second is the dependence of this expectation on common or aggregate shocks. For arguments sake, suppose $E_{t}\left[\ln \left(1+\varepsilon_{r n t}\right)\right]$ exists and is known (up to a finite parameter vector) for some asset $r$. Let $\varepsilon_{r n t}^{*}$ be the deviation of $\ln \left(1+\varepsilon_{r n t}\right)$ about its $F_{t}$-conditional expectation. Then from (2.14)

$$
\varepsilon_{r n t}^{*}=\Delta \ln \left[u_{3}\left(l_{1 n t}, l_{2 n t}, c_{n t}, z_{n t}\right)\right]-E_{t}\left[\ln \left(1+\varepsilon_{r n t}\right)\right]-\ln \left[\beta \pi_{r, t-1}\right] .
$$

Because (2.15) is zero in expection, perhaps parameterizations of $u_{3}\left(l_{1 n t}, l_{2 n t}, c_{n t}, z_{n t}\right)$ could be estimated using instrumental variables. However, the second difficulty arises from the fact that $\varepsilon_{r n t}^{*}$ typically depends on common shocks so that consistent estimates based on equation (2.14) can only be obtained by using time series data but not cross-sectional data. Indeed, Chamberlain $(1984$, p. 1311) remarked "a time average of forecast errors over $T$ 
periods should converge to zero as $T \rightarrow \infty$. But an average of forecast errors across $N$ individuals surely need not converge to zero as $N \rightarrow \infty$; there may be common components in those errors, due to economy-wide innovations."

Conceding the first difficulty, Browning, Deaton and Irish $(1985$, p. 515$)$ and Altonji (1986, p. S181) implicitly assume $\left|\varepsilon_{r n t}\right| \leqslant 1$, disregard the higher order moments in the third line of (2.14), and insert time dummies to deal with the $\ln \left[\beta \pi_{r, t-1}\right]$ term. (MaCurdy (1983) adopts a similar procedure.) Yet maintaining the hypothesis of complete markets yields a straightforward interpretation for parameters estimated from equation (2.14) provided the time dummies included in that equation are redefined appropriately. To see the reason for this, notice that for each $r \in R$, the complete markets hypothesis restricts the forecast errors $\varepsilon_{r n t}$ to be the same for everybody. More precisely, let the data set contain $T$ observations on $N$ households. By comparing (2.7) with (2.10), notice the assumption of complete markets imposes $N T-(N+T)$ restrictions of the form

$$
\lambda_{n t}=\eta_{n} \lambda_{t} .
$$

If markets are complete (2.11) becomes, using (2.16),

$$
\lambda_{t}=\beta E_{t}\left[\lambda_{t+1} \pi_{r t}\right] \text {. }
$$

Denote by $\varepsilon_{r, t+1}$ the error from forecasting $\beta \pi_{r t} \lambda_{t+1} / \lambda_{t}$ at time $t$. Equations (2.14) and (2.17) imply that for all $r \in R$,

$$
\begin{aligned}
\ln \left(1+\varepsilon_{r t}\right)-\ln \left[\beta \pi_{r, t-1}\right] & =\Delta \ln \left(\lambda_{t}\right) \\
& =\Delta \ln \left[u_{3}\left(l_{1 n t}, l_{2 n t}, c_{n t}, z_{n t}\right)\right] .
\end{aligned}
$$

If the term $\ln \left(1+\varepsilon_{r t}\right)-\ln \left[\beta \pi_{r, t-1}\right]$ is treated as a time dummy in the estimation of equation (2.18), then the work cited above can be viewed as consistently estimating household preferences in an economy where a complete set of markets exists. However, it seems these studies have considered the idiosyncratic forecast error $\varepsilon_{r n t}$ as part of the disturbance term and have proceeded to derive their empirical results relying solely on cross-sectional information, thereby encountering (in interpretation, at least) the second difficulty we mentioned above.

\section{AN EMPIRICAL SPECIFICATION}

\section{The Data}

This section briefly describes the data and the parameterization for our empirical work. We used data on a group of households with continuously married heads and spouses between the years 1967 to 1980 as well as time series data on asset returns for the same period. The household data come from the Panel Study of Income Dynamics (PSID). The return data pertain to annual returns on the value-weighted and equally-weighted stock indices on the New York Stock Exchange as well as annual returns on three-month Treasury bills.

Let $t$ stand for the calendar year $(t+1966)$. For each household $n \in\{1, \ldots N\}$, we have data on (a) annual leisure hours for the husband, denoted $l_{1 n t}$, and the 
wife, denoted $l_{2 n t}$, for $t \in\{1, \ldots, 14\}$; (b) real average hourly earnings of husbands, denoted $w_{1 n t}$, and their wives $w_{2 n t}$, for $t \in\{1, \ldots, 14\}$; (c) real household food consumption expenditures, $c_{n t}$, for $t \in\{2,3,4,5,7, \ldots, 14\}$; (d) number of household members $a_{n t}$ for $t \in\{1, \ldots, 14\}$; (e) labor market experience by the husband $t_{n t}$ for $t \in\{1, \ldots, 14\}$; (f) real household income $I_{n t}$ for $t \in\{1, \ldots, 14\}$; (g) real house value $H_{n t}$ for $t \in\{1, \ldots, 14\}$; (h) real rent value and imputed rental value of free housing, $R_{n t}$ for $t \in\{1, \ldots, 14\}$.

An appendix describes in detail how all the variables used in our study were constructed. It also provides a description of the selection criteria used to select a subsample from the total of 6852 households contained in the 1983 PSID data-tapes. Briefly, the subsample was chosen to include households with continuously married couples throughout the fourteen year sample period in which the household head was no older than 46 years in 1967. Households which entered the PSID as part of the (nonrandom) U.S. Census sample or which had missing data on some key variables listed in the Appendix were also excluded. In addition to these general selection criteria (which produced a subsample of 546 households), we imposed further requirements to derive the sample of 434 households that is used in Section 4. These requirements were that the household head had participated in the labor market for every year of the fourteen year sample while the spouse had participated at least once and there were no reporting or coding errors in the variables described above. Table I illustrates some demographic characteristics of the smaller sample. ${ }^{2}$

\section{Parameterizing Preferences and Labor Productivity}

Given $l_{1 n t}$ denotes the husband's leisure in the $n$th family during the $t$ th period, $l_{2 n t}$ the wife's, and $c_{n t}$ the household's current food consumption, we assume $u\left(l_{1 n t}, l_{2 n t}, c_{n t}, z_{n t}\right)$ takes the form

$$
u\left(l_{1 n t}, l_{2 n t}, c_{n t}, z_{n t}\right)=\rho_{0}^{-1} \delta_{0}\left(z_{n t}\right) c_{n t}^{\rho_{0}} l_{2 n t}^{\rho_{2}}+\rho_{1}^{-1} \delta_{1}\left(z_{n t}\right) l_{1 n t}^{\rho_{1}} l_{2 n t}^{\rho_{3}} .
$$

(We assume all other consumption is additively separable with respect to $l_{1 n t}$ and $c_{n t}$.) Observe $u$ is concave increasing in $c_{n t}$ and $l_{1 n t}$ if $\max \left\{\rho_{0}, \rho_{1}\right\} \leqslant 1$. Presumably the household's marginal utility for food depends on the family's size and age composition. Furthermore, given the variety of choices available to shoppers over the degree to which ingredients for snacks and meals are processed, we should think household members spend different amounts of homemaking time in food preparation. So, following Becker (1965), it is plausible to postulate utility from current consumption and male leisure is generated by a home production function which depends nonadditively on female time spent homemaking and market inputs.

\footnotetext{
${ }^{2}$ We also used a somewhat larger sample of households of 497 households to address the issue of sample selection bias due to restricting our main sample to include husbands who had positive hours in every year of the sample. This large sample satisfies the identical selection criteria as the smaller sample except for the fact that both heads and wives were restricted to have positive annual hours in only one year of the 14-year sample.
} 
TABLE 1

Summary Statistics for Sample of 434 Households $^{\text {a }}$

\begin{tabular}{|c|c|c|c|c|c|c|c|c|c|c|c|c|c|c|}
\hline & 1967 & 1968 & 1969 & 1970 & 1971 & 1972 & 1973 & 1974 & 1975 & 1976 & 1977 & 1978 & 1979 & 1980 \\
\hline \multicolumn{15}{|l|}{ Demographic Variables } \\
\hline \multicolumn{15}{|l|}{ (i) Average Age } \\
\hline \multicolumn{15}{|l|}{$\begin{array}{l}\text { of Husband } \\
\text { (ii) Average Age }\end{array}$} \\
\hline of Wife & 32 & & & & & & & & & & & & & \\
\hline $\begin{array}{l}\text { (iii) Average Number } \\
\text { in Family Unit } \\
\text { Hours and Earnings }\end{array}$ & $\begin{array}{c}4.35 \\
(1.64)\end{array}$ & $\begin{array}{c}4.40 \\
(1.55)\end{array}$ & $\begin{array}{c}4.41 \\
(1.57)\end{array}$ & $\begin{array}{c}4.45 \\
(1.55)\end{array}$ & $\begin{array}{c}4.36 \\
(1.53)\end{array}$ & $\begin{array}{c}4.31 \\
(1.55)\end{array}$ & $\begin{array}{c}4.28 \\
(1.52)\end{array}$ & $\begin{array}{c}4.22 \\
(1.48)\end{array}$ & $\begin{array}{c}4.14 \\
(1.46)\end{array}$ & $\begin{array}{c}4.10 \\
(1.41)\end{array}$ & $\begin{array}{c}4.00 \\
(1.37)\end{array}$ & $\begin{array}{c}3.88 \\
(1.34)\end{array}$ & $\begin{array}{c}3.76 \\
(1.32)\end{array}$ & $\begin{array}{c}3.63 \\
(1.29)\end{array}$ \\
\hline $\begin{array}{l}\text { Hours and Earnings } \\
\text { (i) Average Annual }\end{array}$ & \multirow[b]{2}{*}{2366} & & & & & & & & & & & & & \\
\hline Hours of & & 2369 & 2376 & 2359 & 2388 & 2349 & 2363 & 2317 & 2332 & 2296 & 2332 & 2324 & 2279 & 2257 \\
\hline \multicolumn{10}{|l|}{ (ii) Average Annual } & (531) & $(585)$ & (554) & $(574)$ & (607) \\
\hline Hours of Wives & \multirow{2}{*}{$\begin{array}{c}1292 \\
(1486)\end{array}$} & 1127 & 1126 & 1193 & 1184 & 1213 & 1246 & 1256 & 1237 & 1268 & 1282 & 1301 & 1330 & 1423 \\
\hline \multicolumn{13}{|c|}{ (iii) Average Hourly ${ }^{b}$} & & (1068) \\
\hline Earnings of & 4.56 & 4.84 & 5.15 & 5.30 & 5.36 & 5.54 & 5.46 & 5.18 & 5.25 & 5.56 & 5.85 & 5.80 & 5.73 & 5.80 \\
\hline \multicolumn{15}{|l|}{ (iv) Average Hourly $\mathrm{b}^{2}$} \\
\hline Earnings of Wives & 2.65 & 2.63 & 2.82 & 2.86 & 3.03 & 3.08 & 3.07 & 3.00 & 2.91 & 3.28 & 3.42 & 3.02 & 3.03 & 3.17 \\
\hline Who Worked & (3.35) & $(2.78)$ & (3.11) & (3.29) & (3.18) & (3.33) & (3.31) & (4.18) & (3.13) & $(3.75)$ & $(4.06)$ & $(2.75)$ & (3.27) & (3.86) \\
\hline \multicolumn{15}{|l|}{ (v) Proportion of } \\
\hline Worked & 0.50 & 0.50 & 0.07 & 0.04 & 0.57 & 0.50 & 0.08 & 0.00 & 0.07 & 0.00 & 0.00 & 0.12 & 0.10 & 0.14 \\
\hline \multicolumn{15}{|l|}{ Housing, Food } \\
\hline \multicolumn{15}{|l|}{$\begin{array}{l}\text { Consumption, } \\
\text { and Income }\end{array}$} \\
\hline \multicolumn{15}{|l|}{$\begin{array}{l}\text { (i) Average House } \\
\text { b }\end{array}$} \\
\hline Value of & 23169 & 23908 & 25050 & 24767 & 25885 & 27419 & 29602 & 29404 & 29785 & 32792 & 35828 & 39223 & 40805 & 39881 \\
\hline Homeowners & (20578) & (20219) & (20307) & $(18848)$ & $(18710)$ & (18843) & (20048) & (20355) & (20714) & (23212) & (25693) & (29922) & (31163 & (32566) \\
\hline
\end{tabular}




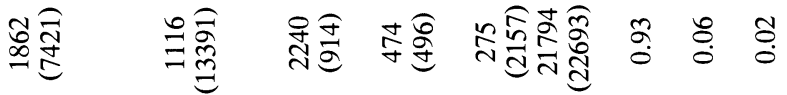

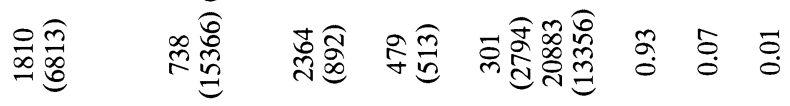

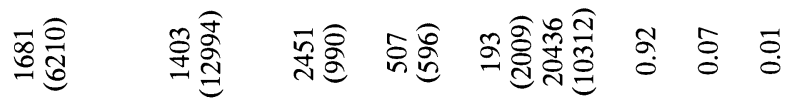

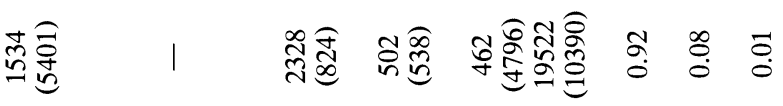

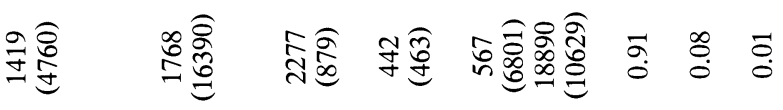

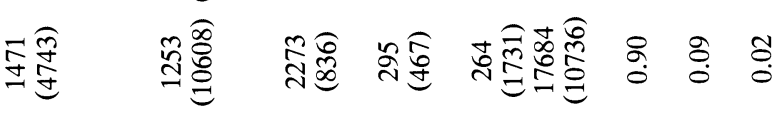

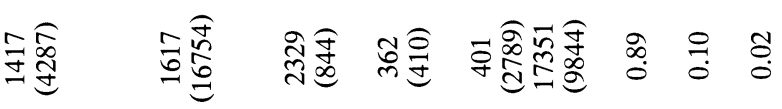

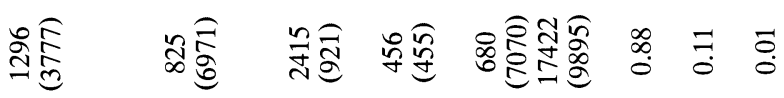

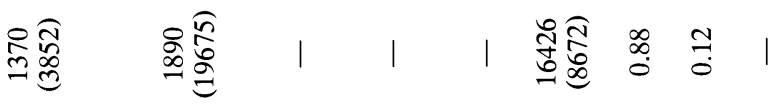

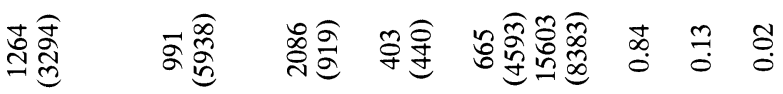

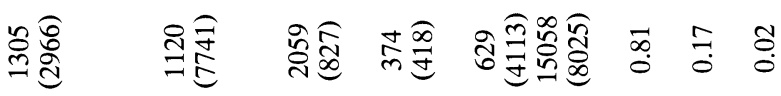

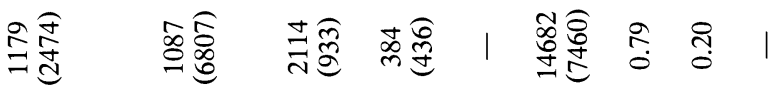

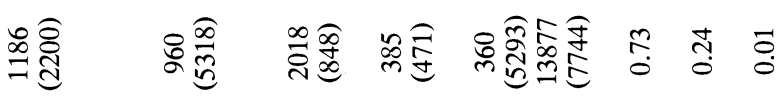

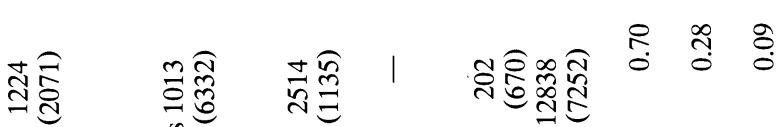

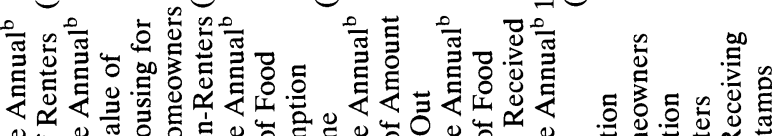

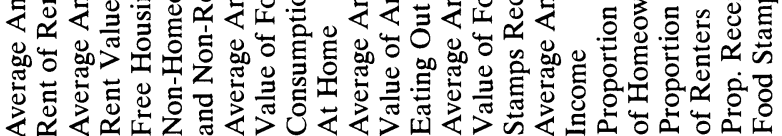
ह 
The utility indices $\delta_{i}\left(z_{n t}\right)$ and the efficiency indices $\gamma_{i}\left(z_{n t}\right)$ are log linear in $z_{n t}$. More specifically, let $x_{n t}$ be a $k \times 1$ column vector of exogenously given socioeconomic time varying attributes of the household such as its size, age, and sex composition, observed by the econometrician. Suppose certain other characteristics denoted by $u_{i n}, v_{i n}, u_{i n t}$, and $v_{i n t}$ are not observed. Letting $B_{i}$ denote $k \times 1$ column vectors of parameters to be estimated, then

$$
\begin{aligned}
& \ln \left[\delta_{i}\left(z_{n t}\right)\right]=x_{n t}^{\prime} B_{i}+u_{i n}+u_{i n t}, \quad i \in\{0,1\}, \\
& \ln \left[\gamma_{1}\left(z_{n t}\right)\right]=x_{n t}^{\prime} B_{2}+v_{1 n}+v_{1 n t} .
\end{aligned}
$$

The disturbance vector $\left(u_{0 n t}, u_{1 n t}, v_{1 n t}, v_{2 n t}\right)$ is distributed independently across households $n \in N$ and period $t \in T$.

The question of whether household preferences are separable in household consumption and nonmarket time has received considerable attention in the labor supply literature. (See, for example, Ghez and Becker (1975), Altonji (1986), and Hotz, Kydland, and Sedlacek (1988).) Our interest in separability is partly motivated by its implications for estimating the intertemporal capital asset pricing model (ICAPM). In our framework, the asset pricing equation, (2.17), can be estimated in conjunction with other equations in the model. For if every household is active each period, $\delta_{0}\left(z_{n t}\right)$ is time-invariant, $\rho_{2}=0$ and markets are complete, estimates of $\beta$ and $\rho_{0}$ can be obtained from aggregate time series data on consumption and asset returns. To see this, solve (2.7) for $c_{n t}$ under the parameterization (3.1), and average over the population to obtain $c_{t}$, average household consumption, which becomes

$$
c_{t}=\lambda_{t}^{1 /\left(\rho_{0}-1\right)} \sum_{n=1}^{N}\left[\eta_{n} l_{2 n t}^{\rho_{2}} \delta_{0}\left(z_{n t}\right)\right]^{1 /\left(\rho_{0}-1\right)} .
$$

Given the conditions above, the second term on the right-hand side of (3.4) is constant so $\left[E\left(c_{n t}\right) / E\left(c_{n, t-1}\right)\right]^{\rho_{0}-1}$ may be substituted for $\lambda_{t} / \lambda_{t-1}$ in (2.17). Then, following Hansen and Singleton (1982), the parameters $\beta$ and $\rho_{0}$ may be estimated using instrumental variables techniques. However, this method is not guaranteed to yield consistent estimates if the periods when households (or maximizing dynasties) are active do not coincide exactly, if $\rho_{2} \neq 0$ or if $\delta_{0}\left(z_{n t}\right)$ is not constant over time.

\section{ECONOMETRIC METHODS AND RESULTS}

\section{Approach}

The econometric ramifications of the framework described in Section 2 are summarized by a simple factor structure, denoted $\left\{\lambda_{t}, w_{t} ; \eta_{n}\right\}_{t \in T ; n \in N}$. It describes how aggregate shocks are transmitted through equilibrium prices to household choices, given the equilibrium distribution for the marginal utilities of wealth across households. While the existence of this simple factor structure provides a convenient way of incorporating the effects of aggregate uncertainty 
into econometrically tractable models of individual choice, it would also be desirable to test the adequacy of this factor structure for describing the observed choices. However the restrictions in (2.16) cannot be tested directly because under the alternative hypothesis that markets are incomplete, the parameters $\lambda_{n t}$ are unidentified. Nevertheless, certain parameters are identified under much weaker assumptions about market structure, a fact MaCurdy (1983) exploits, and this provides a basis for testing the $\left\{\lambda_{t}, w_{t} ; \eta_{n}\right\}$ factor structure.

To describe one test, suppose that under the alternative hypothesis spot markets exist for two or more choice elements which invariably have interior solutions in equilibrium. Then their marginal rate of substitution function can be consistently estimated from cross-sectional data using instrumental variable techniques. Under the null hypothesis of complete markets, the orthogonality conditions associated with that marginal rate of substitution may be augmented with additional orthogonality conditions which come from the marginal utility equation that one of the goods must satisfy in equilibrium. These additional orthogonality conditions reflect an important characteristic of complete markets and Pareto optimality, that the marginal utility of any commodity divided by the marginal utility of wealth is constant across households consuming strictly positive amounts.

The second part of our empirical work addresses some intertemporal implications of the $\left\{\lambda_{t}, w_{t} ; \eta_{n}\right\}$ factor structure, by adding orthogonality conditions derived from the asset pricing equation (2.17) to the econometric structure developed in the first stage. Intuitively, the absence of arbitrage opportunities requires the expected value of the marginal rate of substitution between current and future consumption times the return on any financial asset to equal unity. Under the additional assumption that markets are complete (or that the government acts like a Pareto planner), the marginal rate of substitution, between current consumption now and consumption in any future state of the world, does not vary across households.

We used a Generalized Methods of Moments (GMM) estimator to conduct the empirical investigation. (See Hansen (1982).) Let $j$ denote a particular system of equations, $\alpha_{j}$ the identifiable parameters in that system, $f_{j}\left(\alpha_{j}, n\right)$ a vector of orthogonality conditions for the $n$th observation, and $W_{j}$ a positive definite matrix conformable to $f_{j}\left(\alpha_{j}, n\right)$. Consistent estimates are then obtained by solving for

$$
V_{j}=\min _{\alpha_{j}}\left\{\left[\frac{1}{N} \sum_{n=1}^{N} f_{j}\left(\alpha_{j}, n\right)^{\prime}\right] W_{j}\left[\frac{1}{N} \sum_{n=1}^{N} f_{j}\left(\alpha_{j}, n\right)\right]\right\} .
$$

For our application the smallest asymptotic covariance matrix within this class of estimators is found by making $W_{j}$ the inverse of $\hat{W}_{j} \equiv E\left[f_{j}\left(\alpha_{j}, n\right) f_{j}\left(\alpha_{j}, n\right)^{\prime}\right]$. In this case, the resulting estimator has an asymptotic covariance matrix of $\left(D_{j}^{\prime} \hat{W}_{j}^{-1} D_{j}\right)^{-1}$ where $D_{j} \equiv E\left[\partial f_{j}\left(\alpha_{j}, n\right) / \partial \alpha_{j}\right]$.

Conditioning on the aggregate shocks has ramifications for how to construct the orthogonality conditions and the optimal weighting matrix. Suppose theory 
delivers equations of the form

$$
E_{t}\left[e_{j n t}\left(\alpha_{j}\right)\right]=0 \text {, }
$$

where $e_{j n t}$ is an $r_{j} \times 1$ vector function of the observables and the parameters to be estimated. Orthogonality conditions can be formed for each $t \in\{1, \ldots, T\}$ with a $q$ dimensional instrument vector $y_{n t}$ that satisfies the equation $E_{t}\left(e_{j n t} \otimes y_{n t}\right)=0$. (This conditional expectation is estimated from a sample moment obtained from a cross section of the population.) Unless there are no aggregate shocks $E_{t}\left[\left(e_{j n t} \otimes y_{n t}\right)\left(e_{j n t} \otimes y_{n t}\right)^{\prime}\right]$ depends on $t$. Consequently, rather than averaging over $n$ and $t$ we define the $r_{j} q T$ dimensional vector $f_{j}\left(\alpha_{j}, n\right)$ as

$$
f_{j}\left(\alpha_{j}, n\right)^{\prime}=\left(\left(e_{j n 1} \otimes y_{n 1}\right)^{\prime}, \ldots,\left(e_{j n T} \otimes y_{n T}\right)^{\prime}\right) .
$$

Hence, $\hat{W}_{j}$ is a square $r_{j} q T$ dimensional matrix.

Except where indicated below, the same instruments were used for each component $j$ (which explains why $y_{n t}$ is not subscripted by $j$ ). Here the components of our $14 \times 1$ instrument vector $y_{n t}$ included experience and experience squared of the male $t_{n t}$ and $t_{n t}^{2}$, the logarithm of his wages lagged twice and three times $\ln \left(w_{1 n, t-2}\right)$ and $\ln \left(w_{1 n, t-3}\right)$, family size and family size lagged once $a_{n t}$ and $a_{n, t-1}$, the return on the value-weighted stock return on the NYSE, female leisure lagged twice and three times $\ln \left(l_{2 n, t-2}\right)$ and $\ln \left(l_{2 n, t-3}\right)$, the logarithm of female wages lagged twice (if she worked then) $d_{2 n, t-2} \ln \left(w_{2 n, t-2}\right)$, and the logarithm of the value of a homeowner's house $H_{n t}$, rent $R_{n t}$, and their once lagged values $H_{n, t-1}$ and $R_{n, t-1}$.

\section{Tests of Orthogonality Conditions}

Table II presents our empirical findings. We will now discuss the test statistics obtained, and then conclude the paper with a report on the coefficient estimates and their standard errors. The first two columns in Table II uses data on male labor supply, their wages, and household food consumption to derive estimates of the marginal rate of substitution function between household food consumption and male leisure. Assuming males invariably participate in the labor force, this marginal rate of substitution, hereafter denoted $\operatorname{MRS}\left(l_{1 n t}, c_{n t}\right)$, is the quotient of (2.6), evaluated for $i=1$ with equality, and (2.7). Given the parameterizations adopted in Section 3, it is convenient to take logarithms and then first difference, yielding

$$
\begin{aligned}
\Delta u_{0 n t}-\Delta u_{1 n t}= & \left(\rho_{0}-1\right) \Delta \ln \left(c_{n t}\right)-\left(\rho_{1}-1\right) \Delta \ln \left(l_{1 n t}\right) \\
& +\Delta x_{n t}^{\prime}\left(B_{1}-B_{0}\right)+\left(\rho_{3}-\rho_{2}\right) \Delta \ln \left(l_{2 n t}\right)-\Delta \ln \left(w_{1 n t}\right) .
\end{aligned}
$$

The asymptotic efficiency of this estimator can be increased by adding orthogonality conditions from the (seemingly unrelated) wage equation (2.3), which in $\log$ differenced form, reads

$$
\Delta \ln \left(w_{1 n t}\right)-\Delta x_{n t}^{\prime} B_{2}-\Delta \ln \left(w_{t}\right)=\Delta v_{1 n t} .
$$


The first column of Table II presents estimates of $\operatorname{MRS}\left(l_{1 n t}, c_{n t}\right)$ and the wage functions. ${ }^{3}$ To derive it, consider (4.4), the logged differenced $\operatorname{MRS}\left(l_{1 n t}, c_{n t}\right)$ and (4.5), the wage equation. We now rescale $(4.4)$ by $\left(\rho_{1}-1\right)^{-1}$, multiply the resulting equation by $y_{n t}$ and stack (the 8 years of available data for (4.4) and the 11 years of available data for (4.5)) into the $266 \times 1$ dimensional vector $f_{1}\left(\alpha_{1}, n\right)$ where, with reference to (4.1) through (4.3),

$$
\begin{aligned}
& e_{1 n t}=\left(\left(1-\rho_{1}\right)^{-1}\left(\Delta u_{1 n t}-\Delta u_{0 n t}\right), \Delta v_{1 n t}\right)^{\prime}, \\
& \alpha_{1}=\left(\left(\rho_{0}-1\right) /\left(1-\rho_{1}\right),\left(\rho_{3}-\rho_{2}\right) /\left(1-\rho_{1}\right), 1 /\left(1-\rho_{1}\right),\right. \\
& \left.\quad\left(B_{0}-B_{1}\right) /\left(1-\rho_{1}\right), B_{2}, \Delta \ln \left(w_{t}\right)\right)^{\prime} .
\end{aligned}
$$

Under the null hypothesis that the $j$ th specification is correct, its $N V_{j} \equiv J_{N}$ statistic is distributed $\chi^{2}$ with degrees of freedom (df) equal to the number of overidentifying restrictions. (See Hansen (1982).) On this basis, column (1) of Table II shows that the specification cannot be rejected even at the .1 significance level. ${ }^{4}$ (In the last row of each column we also report the $p$ value, where $1-p$ is the significance level of the overidentifying restrictions.)

Because the estimated standard errors reported in column (1) are so large, we investigated a specialization of (3.2). If the individual effects which scale the two components of (3.1) only differ by a constant, then following MaCurdy (1983), $\operatorname{MRS}\left(l_{1 n t}, c_{n t}\right)$ can be estimated in levels. For in this special case

$$
u_{1 n}-u_{0 n}=\alpha
$$

and so

$$
\begin{aligned}
u_{0 n t}-u_{1 n t}= & \alpha+\left(\rho_{0}-1\right) \ln \left(c_{n t}\right)-\left(\rho_{1}-1\right) \ln \left(l_{1 n t}\right) \\
& +x_{n t}^{\prime}\left(B_{1}-B_{0}\right)+\left(\rho_{3}-\rho_{2}\right) \ln \left(l_{2 n t}\right)+\ln \left(w_{1 n t}\right) .
\end{aligned}
$$

One can test whether estimation via levels versus differences is appropriate. The test stems from the notion that the informational content of $\left(u_{0 n 1}-u_{1 n 1}, \Delta u_{0 n 2}-\Delta u_{1 n 2}, \Delta u_{0 n 3}-\Delta u_{1 n 3}, \ldots\right)$ mimics $\left(u_{0 n 1}-u_{1 n 1}, u_{0 n 2}-\right.$ $\left.u_{1 n 2}, \ldots\right)$, and hence orthogonality conditions based on either sequence estimates the model in levels. Accordingly, we stacked $f_{1}\left(\alpha_{1}, n\right)$ and the 14 dimensional vector $\left(u_{0 n 1}-u_{1 n 1}\right) \otimes y_{n 1} /\left(1-\rho_{1}\right)$ together and reestimated the model with a (new) optimal weighting matrix. Under the null hypothesis (4.7), $N$ times the increment in the criterion function is distributed $\chi^{2}$ with $13 \mathrm{df}$. This

\footnotetext{
${ }^{3}$ Before implementing the estimation and testing strategy described above (which involves constructing orthogonality conditions from (4.1) through (4.4)), we checked for potential sample selection bias that might arise from excluding males who did not participate in every year of our fourteen year sample; a Tobit specification was estimated for male leisure hours and wages to see whether the correlation between the disturbances in the leisure and wage equations is significant. The estimated correlation coefficient $\rho_{22}$ in the larger sample mentioned in the first footnote is positive but small, 0.236. Moreover, the estimated standard error of 0.977 implies a zero value for $\rho_{22}$ cannot be rejected at conventional significance levels. This finding suggests that excluding males who do not participate in every year of our sample should not greatly affect the results derived below.

${ }^{4}$ To calculate regions for a $\chi^{2}$ random variable with $\mathrm{df}$ exceeding 100 , we followed formula 26.4.13 given in Abramowitz and Stegun (1970, p. 941) which approximates its distribution function with $\Phi\left(\sqrt{2 J_{N}}-\sqrt{2 d f-1}\right)$, where $\Phi$ denotes the standard normal distribution function.
} 
TABLE II

\begin{tabular}{|c|c|c|c|c|c|c|c|c|}
\hline & & (1) & (2) & (3) & (4) & (5) & (6) & (7) \\
\hline \multicolumn{9}{|c|}{$\begin{array}{l}\text { Reduced Form Coefficients } \\
\text { (i) MRS }\left(l_{1}, c_{n}\right)\end{array}$} \\
\hline $\ln \left(c_{n t}\right)$ & $\left(\rho_{0}-1\right) /\left(1-\rho_{1}\right)$ & $\begin{array}{c}0.040 \\
(0.247)\end{array}$ & $\begin{array}{c}0.023 \\
(0.148)\end{array}$ & $\begin{array}{c}0.016 \\
(0.094)\end{array}$ & $\begin{array}{c}0.004 \\
(0.039)\end{array}$ & $\begin{array}{c}0.003 \\
(0.035)\end{array}$ & - & - \\
\hline $\ln \left(l_{2 n t}\right)$ & $\left(\rho_{3}-\rho_{2}\right) /\left(1-\rho_{1}\right)$ & $\begin{array}{c}0.279 \\
(0.536)\end{array}$ & $\begin{array}{c}0.235 \\
(0.305)\end{array}$ & $\begin{array}{c}0.278 \\
(0.153)\end{array}$ & $\begin{array}{l}0.278 \\
(0.090)\end{array}$ & $\begin{array}{c}0.279 \\
(0.067)\end{array}$ & $\begin{array}{c}0.200 \\
(0.094)\end{array}$ & $\begin{array}{r}0.0201 \\
(0.064)\end{array}$ \\
\hline $\ln \left(w_{1 n t}\right)$ & $1 /\left(1-\rho_{1}\right)$ & $\begin{array}{c}0.014 \\
(0.157)\end{array}$ & $\begin{array}{c}0.018 \\
(0.087)\end{array}$ & $\begin{array}{c}0.137) \\
0.029 \\
(0.047)\end{array}$ & $\begin{array}{c}0.070) \\
0.036 \\
(0.020)\end{array}$ & $\begin{array}{c}0.037 \\
(0.013)\end{array}$ & $\begin{array}{c}0.029 \\
(0.017)\end{array}$ & $\begin{array}{c}0.030 \\
(0.010)\end{array}$ \\
\hline$a_{1 n t}$ & $\left(B_{0}-B_{1}\right) /\left(1-\rho_{1}\right)$ & $\begin{array}{c}-0.008 \\
(0.024)\end{array}$ & $\begin{array}{c}0.004 \\
(0.021)\end{array}$ & $\begin{array}{c}0.005 \\
(0.012)\end{array}$ & $\begin{array}{c}0.007 \\
(0.007)\end{array}$ & $\begin{array}{l}0.008 \\
(0.005)\end{array}$ & $\begin{array}{c}0.010 \\
(0.007)\end{array}$ & $\begin{array}{r}0.010 \\
(0.003)\end{array}$ \\
\hline 1 & $\alpha /\left(1-\rho_{1}\right)$ & - & $\begin{array}{r}-11.103 \\
(2.944)\end{array}$ & $\begin{array}{r}-11.449 \\
(1.680)\end{array}$ & $\begin{array}{r}-11.381 \\
(0.949)\end{array}$ & $\begin{array}{r}-11.381 \\
(0.625)\end{array}$ & $\begin{array}{r}-10.422 \\
(0.864)\end{array}$ & $\begin{array}{r}-10.425 \\
(0.581)\end{array}$ \\
\hline 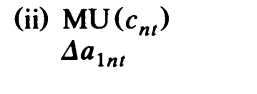 & $B_{0} /\left(1-\rho_{0}\right)$ & - & - & $\begin{array}{c}0.082 \\
(0.059)\end{array}$ & - & - & - & - \\
\hline$\Delta \ln \left(l_{2 n t}\right)$ & $\rho_{2} /\left(1-\rho_{0}\right)$ & - & - & $\begin{array}{c}-0.993 \\
(1.226)\end{array}$ & - & - & - & - \\
\hline (iii) $\underset{\Delta a_{1 n t}}{\operatorname{MU}\left(l_{1 n t}\right)}$ & $B_{1}\left(1-\rho_{1}\right)$ & - & - & - & $\begin{array}{c}-0.020 \\
(0.008)\end{array}$ & $\begin{array}{c}-0.020 \\
(0.007)\end{array}$ & $\begin{array}{c}-0.020 \\
(0.007)\end{array}$ & $\begin{array}{r}-0.020 \\
(0.006)\end{array}$ \\
\hline$\Delta \ln \left(l_{2 n t}\right)$ & $\rho_{3} /\left(1-\rho_{1}\right)$ & - & - & - & $\begin{array}{c}0.140 \\
(0.127)\end{array}$ & $\begin{array}{c}0.140 \\
(0.110)\end{array}$ & $\begin{array}{c}0.140 \\
(0.114)\end{array}$ & $\begin{array}{r}0.140 \\
(0.103)\end{array}$ \\
\hline $\begin{array}{l}\text { (iv) Wage Equation } \\
\Delta\left(t_{1 n t}\right)^{2}\end{array}$ & $B_{2}$ & $\begin{array}{r}-0.030 \\
(0.090)\end{array}$ & $\begin{array}{c}-0.024 \\
(0.088)\end{array}$ & $\begin{array}{r}-0.022 \\
(0.053)\end{array}$ & $\begin{array}{c}-0.028 \\
(0.032)\end{array}$ & $\begin{array}{c}-0.029 \\
(0.031)\end{array}$ & $\begin{array}{c}-0.028 \\
(0.032)\end{array}$ & $\begin{array}{r}-0.028 \\
(0.032)\end{array}$ \\
\hline
\end{tabular}


TABLE II-(Continued)

\begin{tabular}{|c|c|c|c|c|c|c|c|c|}
\hline & & (1) & (2) & (3) & (4) & (5) & (6) & (7) \\
\hline \multirow{7}{*}{$\begin{array}{l}\text { (v) Asset Pricing } \\
\text { Equation } \\
\text { Structural Parameters } \\
\text { (excluding } \beta \text { and } B_{2} \text { ) }\end{array}$} & $\beta$ & - & - & - & - & $\begin{array}{c}0.885 \\
(0.647)\end{array}$ & - & $\begin{array}{c}0.900 \\
(0.702)\end{array}$ \\
\hline & $\rho_{0}$ & $\begin{array}{c}3.900 \\
(40.606)\end{array}$ & $\begin{array}{c}2.280 \\
(13.641)\end{array}$ & $\begin{array}{c}1.540 \\
(4.021)\end{array}$ & $\begin{array}{c}1.120 \\
(1.104)\end{array}$ & $\begin{array}{c}1.083 \\
(0.979)\end{array}$ & - & - \\
\hline & $\rho_{1}$ & $\begin{array}{l}-71.470 \\
(822.164)\end{array}$ & $\begin{array}{l}-55.640 \\
(280.425)\end{array}$ & $\begin{array}{r}-33.608 \\
(56.000)\end{array}$ & $\begin{array}{c}-26.853 \\
(15.280)\end{array}$ & $\begin{array}{r}-26.345 \\
(9.986)\end{array}$ & $\begin{array}{c}-33.784 \\
(20.302)\end{array}$ & $\begin{array}{r}-32.560 \\
(11.660)\end{array}$ \\
\hline & $\rho_{2}$ & - & - & $\begin{array}{c}0.536 \\
(3.945)\end{array}$ & $\begin{array}{r}-3.850 \\
(4.882)\end{array}$ & $\begin{array}{c}-3.801 \\
(4.471)\end{array}$ & $\begin{array}{c}-2.075 \\
(6.498)\end{array}$ & $\begin{array}{r}-2.050 \\
(5.000)\end{array}$ \\
\hline & $\rho_{3}$ & - & - & $\begin{array}{c}10.150 \\
(21.410)\end{array}$ & $\begin{array}{c}3.892 \\
(4.107)\end{array}$ & $\begin{array}{c}3.823 \\
(3.561)\end{array}$ & $\begin{array}{c}4.884 \\
(4.242)\end{array}$ & $\begin{array}{c}4.696 \\
(3.610)\end{array}$ \\
\hline & $B_{0}$ & - & - & $\begin{array}{c}-0.044 \\
(0.328)\end{array}$ & $\begin{array}{c}-0.342 \\
(0.292)\end{array}$ & $\begin{array}{r}-0.337 \\
(0.275)\end{array}$ & $\begin{array}{r}-0.362 \\
(0.348)\end{array}$ & $\begin{array}{r}-0.353 \\
(0.279)\end{array}$ \\
\hline & $B_{1}$ & - & - & $\begin{array}{r}-0.230 \\
(0.450)\end{array}$ & $\begin{array}{r}-0.550 \\
(0.346)\end{array}$ & $\begin{array}{c}-0.548 \\
(0.264)\end{array}$ & $\begin{array}{c}-0.693 \\
(0.448)\end{array}$ & $\begin{array}{r}-0.678 \\
(0.315)\end{array}$ \\
\hline \multirow[t]{4}{*}{ Test Statistics } & & & & & & & & \\
\hline & $J_{N}$ & 252.23 & 289.19 & 382.33 & 420.54 & 434.22 & 421.24 & 439.57 \\
\hline & df & 250 & 263 & 365 & 404 & 412 & 405 & 413 \\
\hline & $p$ value & .548 & .871 & .742 & .722 & .782 & .719 & .824 \\
\hline
\end{tabular}


test is an example of a general class we repeatedly use below; suppose the null hypothesis imposes $\Delta j$ extra orthogonality conditions in addition to the $j$ imposed under the alternative, and there are $\Delta k$ additional parameters to estimate, where $\Delta j$ is greater than $\Delta k$. Then the test statistic $N\left(V_{j+\Delta j}-V_{j}\right)$ is distributed $\chi^{2}$ with $(\Delta j-\Delta k)$ df. (See Gallant and Jorgenson (1979), and Eichenbaum, Hansen, and Singleton (1988).) In this case the test statistic is 13.4; therefore (4.7) cannot be rejected at the .05 significance level. Hence the remaining parts of the work reported here impose (4.7) and exploit (4.8), the logged MRS $\left(l_{1 n t}, c_{n t}\right)$ in level form, rather than its first difference (4.4).

Rescaling $(4.8)$ by $1 /\left(1-\rho_{1}\right)$, multiplying the resulting equations by $y_{n t}$, and stacking, we obtain a $280 \times 1$ vector $f_{2}\left(\alpha_{2}, n\right)$, implicitly defined by

$$
\begin{aligned}
& e_{2 n t}=\left(\left(u_{1 n t}-u_{0 n t}\right) /\left(1-\rho_{1}\right), \Delta v_{1 n t}\right)^{\prime}, \\
& \alpha_{2}=\left(\alpha_{1}^{\prime}, \alpha\right)^{\prime} .
\end{aligned}
$$

Although the significance level for the overidentifying restrictions is lower in column (2) than column (1), the .13 value obtained still lies well outside the critical region, as it is usually defined, and the estimated standard errors fall substantially.

Our first test of the simple factor structure $\left\{\lambda_{t}, w_{t} ; \eta_{n}\right\}$ is derived by adding the condition associated with the household's marginal utility of consumption in equilibrium, denoted $\mathrm{MU}\left(c_{n t}\right)$, to the orthogonality conditions formed from (4.8) and (4.5). The idea is to see whether the data reject the additional orthogonality conditions formed from differencing the logarithm of (2.7), namely

$$
\Delta x_{n t}^{\prime} B_{0}+\left(\rho_{0}-1\right) \Delta \ln \left(c_{n t}\right)+\rho_{2} \Delta \ln \left(l_{2 n t}\right)-\Delta \ln \left(\lambda_{t}\right)=-\Delta u_{0 n t} .
$$

Column (3) reports the parameter estimates and test statistics associated with adding the extra conditions. They are obtained by augmenting $f_{2}\left(\alpha_{2}, n\right)$ with those from (4.10) to form $f_{3}\left(\alpha_{3}, n\right)$; it is a $392 \times 1$ vector. Observe the coefficient on household consumption and its difference is restricted across (4.8) and (4.10). The $3 \times 1$ disturbance $e_{2 n t}$ and the parameter vector $\alpha_{2}$ are defined as

$$
\begin{aligned}
& e_{3 n t}=\left(e_{2 n t}, \Delta u_{0 n t} /\left(1-\rho_{0}\right)\right)^{\prime}, \\
& \alpha_{3}=\left(\alpha_{2}^{\prime}, B_{0} /\left(1-\rho_{0}\right), \rho_{2} /\left(1-\rho_{0}\right), \Delta \ln \left(\lambda_{t}\right) /\left(1-\rho_{0}\right)\right)^{\prime} .
\end{aligned}
$$

The $p$ value listed in column (3) of Table II shows that this specification is not rejected either, and the estimated standard errors are lower than specification (2). Another way of testing the simple factor structure is to focus on the additional orthogonality conditions it yields. Again we find no evidence against the simple factor structure; the extra orthogonality conditions generated by (4.10), over those derived from (4.5) and (4.8), cannot be rejected at conventional levels of significance. (The test statistic is 93 and there are $102 \mathrm{df}$ under the null.)

Instead of using (4.10) one could equivalently augment the orthogonality conditions formed from (4.5) and (4.8) with some from (2.9) (or its differenced logarithm). The latter condition is associated with the husband's marginal utility 
of leisure in equilibrium, denoted MU $\left(l_{1 n t}\right)$. Given our empirical specification, this is

$$
\begin{aligned}
& \Delta x_{n t}^{\prime} B_{1}+\left(\rho_{1}-1\right) \Delta \ln \left(l_{1 n t}\right)+\rho_{3} \Delta \ln \left(l_{2 n t}\right)-\Delta \ln \left(w_{1 n t}\right)-\Delta \ln \left(\lambda_{t}\right) \\
& \quad=-\Delta u_{1 n t}
\end{aligned}
$$

providing an interior solution for $l_{1 n t}$ can be assured. (Notice that any two of (4.4), (4.10), and (4.12) imply the third.) The results are presented in Column (4). Now orthogonality conditions constructed from (4.12) are used to augment $f_{2}\left(\alpha_{2}, n\right)$. Denote the new set $f_{4}\left(\alpha_{4}, n\right)$; it is a $434 \times 1$ dimensional vector because (4.12) may be evaluated for $t \in\{4, \ldots, 14\}$. Noting the single cross-equation restriction on the coefficient of $\Delta \ln \left(l_{1 n t}\right)$, the disturbance $e_{4 n t}$ and the parameter vector $\alpha_{4}$ are respectively defined as

$$
\begin{aligned}
& \left.e_{4 n t}=\left(e_{2 n t}, \Delta u_{1 n t}\right) /\left(1-\rho_{1}\right)\right)^{\prime}, \\
& \alpha_{4}=\left(\alpha_{2}^{\prime}, B_{1} /\left(1-\rho_{1}\right), \Delta \ln \left(\lambda_{t}\right) /\left(1-\rho_{1}\right)\right)^{\prime} .
\end{aligned}
$$

The results are comparable to specification (3). Presumably the differences in the standard errors can be attributed to the increased number of orthogonality conditions associated with the extra years of data. (Recall from Section 3 that data on household food consumption was not available for years 1 and 6.)

To capture the intertemporal aspects of our model, we adapt, to a GMM setting, the analyses of Chetty (1968) and Zellner (1971) for linear models which pool time series data with cross sectional data. Here we must assume that aggregate shocks are stationary and ergodic. A vector of asset returns, denoted $\pi_{1 t}$, is substituted into the asset pricing equation (2.17) and another vector of asset returns, $\pi_{2 t}$, serve as instruments, after being lagged once. The orthogonality conditions become

$$
f\left(\alpha_{5}, t\right)=\left[\beta \pi_{\sim 1 t}\left(\lambda_{t+1} / \lambda_{t}\right)-1\right] \otimes \underset{\sim 2, t-1}{\pi_{2}}
$$

where $\alpha_{5}=\left(\alpha_{4}^{\prime}, \beta\right)^{\prime}$. Then $f_{4}\left(\alpha_{4}, n\right)$ and $f\left(\alpha_{5}, t\right)$ are combined by defining $f_{5}\left(\alpha_{5}, s\right)$ for $s \in\{1, \ldots, N+T\}$ as

$$
f_{5}\left(\alpha_{5}, s\right)^{\prime}=\left\{\begin{array}{lll}
\left(f_{4}\left(\alpha_{4}, s\right)^{\prime}, 0\right) & \text { if } & 1 \leqslant s \leqslant N, \\
\left(0, f\left(\alpha_{5}, s-N\right)^{\prime}\right) & \text { if } & N<s \leqslant N+T .
\end{array}\right.
$$

Because $e_{4 n t}$ is orthogonal to the forecast error in the asset pricing equation, it follows that $E\left[f_{5}\left(\alpha_{5}, s_{0}\right) \otimes f_{5}\left(\alpha_{5}, s_{1}\right)^{\prime}\right]=0$ whenever $s_{0} \neq s_{1}$. Upon substituting the sample moment for $E\left[f_{5}\left(\alpha_{5}, s\right) \otimes f_{5}\left(\alpha_{5}, s\right)^{\prime}\right]$ into the criterion function, some matrix algebra shows $V_{5}$, defined in (4.1) by setting $j=5$ and replacing $N$ with $N+T$, simplifies to

$$
\begin{aligned}
& (N+T) V_{5}= \\
& \min _{\alpha_{5}}\left\{\left[\sum_{n=1}^{N} f_{4}\left(\alpha_{4}, n\right)^{\prime}\right]\left[\sum_{n=1}^{N} f_{4}\left(\alpha_{4}, n\right) f_{4}\left(\alpha_{4}, n\right)^{\prime}\right]^{-1}\left[\sum_{n=1}^{N} f_{4}\left(\alpha_{4}, n\right)\right]\right. \\
& \left.\quad+\left[\sum_{t=1}^{T} f\left(\alpha_{5}, t\right)^{\prime}\right]\left[\sum_{t=1}^{T} f\left(\alpha_{5}, t\right) f\left(\alpha_{5}, t\right)^{\prime}\right]^{-1}\left[\sum_{t=1}^{T} f\left(\alpha_{5}, t\right)\right]\right\}
\end{aligned}
$$


when the optimal weighting matrix is used. We used three annual return series, namely, the returns on the value-weighted stock index on the New York Stock Exchange (NYSE), the equally-weighted stock index on the NYSE and the return on 3-month Treasury bills. Hence, $\pi_{1 t}$ and $\pi_{2 t}$ are both $3 \times 1$ vectors, and the total number of orthogonality conditions for this specification is 443 . This specification is not rejected by the data either. Comparing (5) with (4), we find the significance of the 8 extra orthogonality conditions (4.14) derived from the ICAPM is 0.1 . These results contrast with those from the earlier studies we cited of the ICAPM using aggregate data.

\section{Parameter Estimates}

The structural parameter estimates are derived from the estimates of the reduced form parameters; for specifications (3) through (5), all the structural parameters are exactly identified because, as we mentioned earlier, the single over-identifying restriction in these specifications was imposed during estimation of the reduced form parameters. Their standard errors and those of the identified parameters in specifications (1) and (2) were derived using the delta method. As can be seen, the most precise estimates (of both the reduced form and structural coefficients) are found in column (5). They lie within an estimated standard deviation of the corresponding numbers in the other columns. Most of the ensuing discussion is therefore devoted to them.

Our most precise estimate of $\rho_{1}$ (the exponent for male leisure) is -26 . (Thus preferences over leisure are concave increasing, as required by the theory.) Equivalently, $-\left(1-\rho_{1}\right)^{-1}$, the elasticity of male leisure with respect to wages, holding fixed the marginal utility of wealth, is (highly significantly) estimated as -0.037 . Similarly, $l_{1 n t}\left[\left(1-l_{1 n t}\right)\left(1-\rho_{1}\right)\right]^{-1}$ is the elasticity of male labor supply when the marginal utility of wealth is held constant. ${ }^{5}$ Noting the average proportion of time spent working is about .25 , the implied elasticity at this work level is about .11, which lies well within the cluster of numbers reported in MaCurdy (1981), Browning, Deaton, and Irish (1985), and Altonji (1986). ${ }^{6}$ Similarly we find wages are concave in experience (because our estimate of $B_{2}$ is negative).

Our results show female leisure is nonseparable with household food consumption and/or male leisure. The null hypothesis that

$$
0=\left(\rho_{3}-\rho_{2}\right) /\left(1-\rho_{1}\right)=\rho_{3} /\left(1-\rho_{1}\right)
$$

is strongly rejected from the covariance matrix associated with the reduced form; the test statistic, 24.7, is distributed $\chi^{2}$ with $2 \mathrm{df}$ under the null. However neither estimate of $\rho_{2}$ nor $\rho_{3}$ significantly differs from 0 , so one cannot confidently infer exactly what type of nonseparability is present here.

\footnotetext{
${ }^{5}$ This formula is easily derived from the first order condition for male leisure (2.9), or its parameterized, lag differenced, form (4.9), using the definition that unstandardized hours worked is $1-l_{1 n t}$.

${ }^{6}$ All these results lie within the range of findings for earlier, second generation static model, studies. See pp. 193-194 of Killingsworth (1983) for a summary of this earlier literature.
} 
The Frisch elasticity of hours worked by husbands with respect to family size is $l_{1 n t} a_{n t} B_{1} /\left(1-l_{1 n t}\right)\left(\rho_{1}-1\right)$. Thus the column (5) estimate of $B_{1},-0.548$, translates to an elasticity of .24 for $a_{n t}=4$ and $l_{1 n t}=0.75$. The positive sign on this elasticity, also found by Browning, Deaton, and Irish (1985), might suggest the household is not free to smooth the husband's leisure over the childrearing phase (by running down savings and, if necessary, borrowing to purchase the market good offspring consume, rather than working harder). An alternative explanation, consistent with the hypothesis that markets are complete, is that offspring reduce the husband's marginal utility of leisure by crowding the household and competing for the wife's time.

Our estimate of $\beta$, the subjective discount factor, is 0.89 , a plausible value for annual data. Perhaps the most disturbing finding is that all the estimates of $\rho_{0}$ (the exponent for food consumption) exceed 1 . If true, preferences would be convex increasing in food consumption, thus invalidating the first order condition (2.7). It would, however, be premature to argue that this counterintuitive finding constitutes strong evidence against the hypothesis that markets are complete. The most unreasonable estimates of $\rho_{0}$ are found in columns (1) and (2), where orthogonality conditions derived from the marginal rate of substitution and wage functions alone are exploited in estimation. If anything, imposing the simple factor structure pushes our estimates of $\rho_{0}$ towards the theoretically acceptable region.

Furthermore, neither the structural estimates of $\rho_{0}$ nor the reduced form estimates of $\left(\rho_{0}-1\right) /\left(1-\rho_{1}\right)$ differ significantly from 0 . It is worth noting that if preferences over consumption are linear $\left(\rho_{0}=1\right)$, under our specification, each household spends (with probability one) its total wealth on consumption at one, optimally chosen, point in time! Consequently this particular specification of the model was not investigated. Setting $\rho_{0}=0$ corresponds to the logarithmic specification

$$
u\left(l_{1 n t}, l_{2 n t}, c_{n t}, z_{n t}\right)=\delta_{0}\left(z_{n t}\right) \ln \left(c_{n t}\right) l_{2 n t}^{\rho_{2}}+\rho_{1}^{-1} l_{1 n t}^{\rho_{1}} l_{2 n t}^{\rho_{3}} .
$$

There are three, asymptotically equivalent, ways to test this restriction. The first is to equate the negative of the coefficient on $\ln \left(c_{n t}\right)$ with the one on $\ln \left(w_{1 n t}\right)$ in $\operatorname{MRS}\left(l_{1 n t}, c_{n t}\right)$. Second, the estimated standard error of the structural parameter $\rho_{0}$, gives a more direct test. Under both specifications (4) and (5), neither test rejects the logarithmic specification (4.18). A third method is to check how much the criterion function deteriorates when the extra restriction is imposed. The results of the third test are reported in column (6) and (7) of Table II. Comparing (4) with (6) the test statistic is 0.70 but comparing (5) with (7) the corresponding number is 5.35. (Under the null hypothesis that $\rho_{0}=0$, the test statistic is distributed $\chi^{2}$ with $1 \mathrm{df}$.) Similarly specification (7) is rejected against specification (6) at the .05 (but not the .01) level. Perhaps jointly imposing logarithmic preferences over consumption and the simple factor structure of complete markets is overrestrictive for a framework which seeks to reconcile data on individual household choices with data on returns to financial assets. But this suggestion should be balanced against some other features of specification (7): it is not 
TABLE III

\begin{tabular}{ccc}
\hline \hline$t$ & $\lambda_{t} / \lambda_{t-1}$ & $w_{t} / w_{t-1}$ \\
\hline 4 & 0.955 & 1.014 \\
& $(0.432)$ & $(0.051)$ \\
5 & 1.218 & 1.040 \\
& $(0.225)$ & $(0.044)$ \\
6 & 0.896 & 1.050 \\
& $(0.240)$ & $(0.050)$ \\
7 & 1.085 & 1.001 \\
& $(0.340)$ & $(0.045)$ \\
8 & 0.738 & 0.945 \\
& $(0.232)$ & $(0.037)$ \\
9 & 1.051 & 1.021 \\
& $(0.291)$ & $(0.045)$ \\
10 & 0.937 & 1.070 \\
& $(0.107)$ & $(0.043)$ \\
11 & 1.381 & 1.081 \\
& $(0.251)$ & $(0.038)$ \\
12 & 0.972 & 1.007 \\
& $(0.150)$ & $(0.037)$ \\
13 & 0.812 & 0.982 \\
& $(0.133)$ & $(0.041)$ \\
14 & 1.000 & 1.037 \\
& $(0.163)$ & $(0.043)$ \\
\hline
\end{tabular}

rejected against the unspecified alternative, nor against the $\operatorname{MRS}\left(l_{1 n t}, c_{n t}\right)$ and wage specification (2), and the coefficients on the other parameters are not significantly affected by setting $\rho_{0}=0$. In any event, the data do not precisely determine how concave household preferences are over consumption.

The high values obtained for $\rho_{0}$ may also help explain why we find the paradoxical result that increasing family size reduces the marginal utility from household food consumption. (All our estimates of $B_{0}$ are negative.) This is most easily seen from specification (3); the minimized criterion function, $V_{3}$, picks up the positive correlation between family size $a_{n t}$ and food consumption $c_{n t}$ via the reduced form coefficient $B_{0} /\left(1-\rho_{0}\right)$ in the first order condition. Thus the estimate of $B_{0}$ has the same sign as $\left(1-\rho_{0}\right)$, and for similar reasons, our point estimate of $B_{0}$ declines with that of $\rho_{0}$ in specifications (4) through (6).

An observation the introduction made to motivate this paper was that aggregate shocks have been previously detected in studies of panel data. Table III exhibits the estimates implied from specification (5) of $\left\{\lambda_{t+1} / \lambda_{t}\right\}_{t=4}^{14}$ and $\left\{w_{t+1} / w_{t}\right\}_{t=4}^{14}$. Recall $w_{t+1} / w_{t}$ measures the (ex post) change in real wages; also $\beta \lambda_{t+1} / \lambda_{t}$ is the date 0 price of a contingent claim to consumption for the particular realization in period $(t+1)$, divided by the corresponding price in period $t$. In our model of competitive equilibrium, these prices enter the estimation framework through the two sequences of time dummies, $\left\{\left(\rho_{1}-1\right)^{-1} \Delta \ln \left(\lambda_{t}\right)\right\}_{t=4}^{14}$ and $\left\{\Delta \ln \left(w_{t}\right)\right\}_{t=4}^{14}$. This paper concludes by reaffirming the importance of aggregate shocks. Under the null hypothesis that there are no aggregate shocks $\left(\rho_{1}-1\right)^{-1} \Delta \ln \left(\lambda_{t}\right)=\left(\rho_{1}-1\right)^{-1} \Delta \ln \left(\lambda_{s}\right)$ and $\Delta \ln \left(w_{t}\right)=$ 
$\Delta \ln \left(w_{s}\right)$ for all $s$ and $t$. The test statistic obtained from imposing the first 10 equalities, a $\chi^{2}$ with $10 \mathrm{df}$ under the null, is 22.8 ; the analogous test statistic for the second 10 is 23.7 . We therefore reject the two null hypotheses that aggregate effects are not present in panel data on household food consumption and male labor supply.

Department of Economics, University of Minnesota, Minneapolis, MN 55455, U.S.A.

and

Graduate School of Industrial Administration, Carnegie Mellon University, Pittsburgh, PA 15213, U.S.A.

Manuscript received July, 1987; final revision received August, 1989.

\section{APPENDIX}

The samples on male household heads and their wives used in the text were drawn from the 1968-1983 Family File of the PSID data tapes. From the total of 6,852 households included in the survey as of 1983, we selected households composed of couples who had remained married throughout the survey period 1968 to 1983 , and had heads who were no older than 46 years in the initial survey year 1968. In addition, we eliminated households that came from the nonrandom U.S. Census sample, who did not have a usable variable for the age of the household head, the sex of the household head, the age of the wife, the education of the head, and the age of the youngest child for any of the survey years from 1968 to 1981 . When applied to the original sample of 6,852 households, these selection criteria produced a sample of 546 continuously married households for the survey period 1968 to 1981 , with heads no older than 46 years in the survey year 1968 and without missing data on the above-mentioned variables. The losses associated with each criterion applied consecutively to the original sample were as follows:

(i) Households in which there occurred a change in either the head or wife during the 16-year survey period from 1968 to 1983 were excluded. Loss: 4,912 households.

(ii) Households that had been surveyed as part of the nonrandom U.S. Census sample in 1968 were excluded. Loss: 765 households.

(iii) Households that had heads older than 46 in the 1968 survey year were excluded. Loss: 526 households.

(iv) Households with missing data for the education of the head were excluded. Loss: 1 household.

(v) Unmarried (single) households were excluded. Loss: 68 households.

(vi) Households with missing data on the age of youngest child were excluded. Loss: 34 households.

The data refer to the period 1967 to 1980 . This is because the individual data collected by the PSID in a given survey year corresponds (aside from some exceptions noted below) to variables pertaining to the previous calendar year. We now turn to the description of the variables used in our study and the additional selection criteria used to obtain the two subsamples from which our empirical results are derived.

Our measures of annual hours and average hourly earnings are identical to the PSID variables of the same names. In the PSID data tapes, average hourly earnings for both husbands and wives are defined from the ratio of total labor income to total annual hours of work. This measure does not distinguish between labor income deriving from straight versus overtime work, from the existence of multiple jobs at a point in time or from different jobs during the year. On the other hand, use of this measure (as opposed to the hourly wage at a point in time) implies that both salaried and self-employed individuals in addition to hourly-rated workers can be included in our sample. It also avoids a potential timing problem in the measurement of hours and wages to which Altonji (1986) refers; i.e. for individuals who did report an hourly wage rate, this corresponds to the wage at the time of the interview for the survey (which occurs sometime in the first half of the year) while hours worked refers to annual hours in the preceding calendar year. 
We used these measures of average hourly earnings and average annual hours to select two subsamples from the samples of 546 households. The first was chosen such that the head had positive annual hours for every year of the sample period and the wife had positive annual hours for at least one year. However, we encountered cases (due to reporting or coding errors) for which annual hours were positive but average hourly earnings zero or vice versa. Likewise, we found cases for which annual hours exceeded our estimate for annual leisure hours, namely, 8760. Finally, there is an issue about the way average hourly earnings was coded in 1968 versus the remaining survey years. In 1968 , 9's were coded instead of 0 's when the head or wife did not work for money and therefore had no hourly earnings. In the remaining years, average hourly earnings above 99.99 dollars were coded as 99.99 dollars. We eliminated an entire observation if any one of these reporting or coding errors occurred in some year for a given individual. This lead to the sample 434 households on which our main results are based.

The second subsample was solely used to answer the question of sample selection bias due to excluding males who did not participate every period. It was chosen by assuming that the head had positive annual hours and positive hourly earnings for at least one year of the sample period. This produced a subsample of 497 households. For this subsample, we did not eliminate an entire observation when we encountered a reporting or coding error in some year for a given individual. However, we did eliminate those person-years from the estimation. This produced a loss of 78 person-years.

The PSID data-tapes do not contain a direct measure of food consumption expenditures. We followed two steps to obtain the empirical measure for food consumption expenditures. First, we obtained a variable corresponding to food expenditures for a given year by summing the values of annual food expenditures for meals at home, annual food expenditures for eating out, and the value of food stamps received for that year. We then measured consumption expenditures for year $t$ by taking 0.25 of the value of this variable for year $t-1$ and 0.75 of its value for year $t$. As in Hall and Mishkin (1982), the second step was taken to account for the fact that the survey question used to elicit information about household food consumption is asked sometime in the first half of the year, while the response is dated in the previous year.

The variables used in the construction of the measure for total food expenditures are also subject to the problem of truncation from above in the way they are coded in the 1983 PSID data tapes. The truncation value for the value of food stamps received in the 1968 survey year is 999 dollars while the relevant value for this variable in the subsequent years and for the value of food consumed at home and eating out is 9,999 dollars. We eliminated only the particular year for which such upper bounds were binding for the consumption variable but not the observation for the household for all years of the sample. We lost 12 person-years due to the truncation of the consumption variable, 1 person-year due to truncation of the value of food eating out and 11 person-years due to truncation of the value of food consumed at home.

We also constructed an experience variable for the head of the household. This variable was constructed as age minus education minus six. The education variable was in turn constructed from a polytomous variable defined to equal:

1 if number of grades attended was between 0 and 5 ,

2 if number of grades attended was between 6 and 8 ,

3 if number of grades attended was between 9 and 11 ,

4 if the husband attended 12 grades,

5 if the husband has a high school degree plus non-academic training,

6 if the husband had attended college but not earned a degree,

7 if the husband had earned a B.A. but no advanced degree,

8 if the husband had earned both a B.A. and advanced or professional degree,

9 if the husband cannot read or write or has trouble reading or writing.

The education variable was obtained as three times the value of this variable whenever its value was less than or equal to four. Otherwise, the education variable was defined to equal eight plus the value of the polytomous variable. We constructed the education variable in this way because the variable corresponding to the number of years of schooling is not consistently measured across the different years of the PSID.

We also constructed some additional variables that were used as instruments in the parts of our study employing instrumental variables estimation. The variable showing the value of homeownership was constructed by multiplying the value of a household's home by an indicator variable determining ownership. A similar procedure was followed to generate the variable of the above variables showing the value of rent paid and rental value of free housing for a household. Finally, household income was 
measured from the PSID variable total family money income, which includes taxable income of head and wife, total transfers of head and wife, taxable income of others in the family units, and their total transfer payments. The issue of truncation from above also arises for the variables used to construct measures of the above variables. The variables for house value are coded in the 1983 PSID data-tapes under two different field-widths: for the survey years 1968 to 1974, the field-width is 5 and the appropriate upper limit is 99,999 dollars while for 1975 to 1981 , the field-width is 6 and the truncation value is 999,999 dollars. Likewise, the field-widths and truncation values for the variable total family money income vary across different years of the survey: for 1968 to 1979 , the field-width is 5 and truncation value 99,999 dollars; for 1980, the relevant numbers are 6 and 999,999 dollars, while for 1981 , they are 7 and 9,999,999 dollars, respectively. Finally, the variables denoting the value of rent paid and rental value of free housing both face upper values of 9999 dollars. When applied to the sample of 434 households, these upper limits turned out to be binding for 4 person-years for house value, 21 person-years for family income. However, we did not eliminate any observations or person-years due to the existence of such upper limits because the fact that some of the variables used as instruments were truncated from above for certain years does not invalidate the use of these instruments.

The variables described above such as average hourly earnings, household income, etc. are recorded in the PSID data-tapes in nominal terms. We used two different deflators to convert such nominal quantities to real. First, we defined the (spot) price of food consumption to be the numeraire good at $t$ in the theoretical framework of Section 2 . We accordingly measured real food consumption expenditures and real wages as the ratio of the nominal consumption expenditures and wages and the annual implicit price deflator for food consumption expenditures published in Table 7.12 of the National Income and Product Accounts. (See the U.S. Department of Commerce, Bureau of Economic Analysis publication The National Income and Product Accounts of the U.S., 1929-1974 and the Survey of Current Business, July, 1977 and July 1982 issues.) On the other hand, when calculating real annual returns for the financial variables used in our study, we used the annual implicit price deflator for personal consumption expenditures, including expenditures for durable and nondurable goods and services to obtain a measure of the annual inflation rate. If there is year-to-year variation in the price of food consumption relative to the price of total personal consumption, then the (inverse) of this relative price will appear in the estimated asset pricing equation of Section 4. This potential price variation over time, shown in Table A.3, is accounted for in the asset-pricing relationship that we estimated. Finally, we deflated variables such as the nominal value of homeownership or nominal family income by the implicit price deflator for total personal consumption expenditures. Since these latter variables appear only as instruments, it is immaterial which price deflator is used in their construction. Table I provides some summary statistics about the household data used in our study. In this table, all nominal variables have been converted to 1972 dollars by using the appropriate deflators. The summary statistics in this table are based on the subsample of 434 households, including the truncated values for some of the variables. Inclusion of the truncated values only implies that the magnitudes of the sample means and standard deviations are somewhat underestimated.

In addition to the individual data recorded in the PSID, we used measures on two types of financial returns. The first type of return is an (annual) stock return defined to include dividends. This was measured in two different ways. The first measure was calculated from the monthly returns on the value-weighted stock price index for stocks on the New York Stock Exchange. The other measure was calculated for the equally-weighted stock price index. The monthly rate of return series were taken from the CRSP tapes. The (gross) annual rate of return for the two stock price indices were calculated according to the geometric average

$$
\pi_{r t}=\prod_{j=1}^{12}\left(1+r_{t j}\right) /\left(1+\pi_{t}\right), \quad r=1,2,
$$

where $r_{t j}$ is the monthly nominal rate of return for year $t$, month $j$, and $\pi_{t}$ is the annual inflation rate between $t$ and $t-1$. To measure the gross annual inflation rate $1+\pi_{t}$, we took the ratios of the annual implicit consumption deflators. The second type of return that we used in our study is the gross annual return on 3-month Treasury bills. We used monthly data on nominal yearly rates of return for 3-month Treasury bills to construct this series. This monthly rate of return series was taken from the CITIBASE data tapes. (For its primary source, see Board of Governors of the Federal 


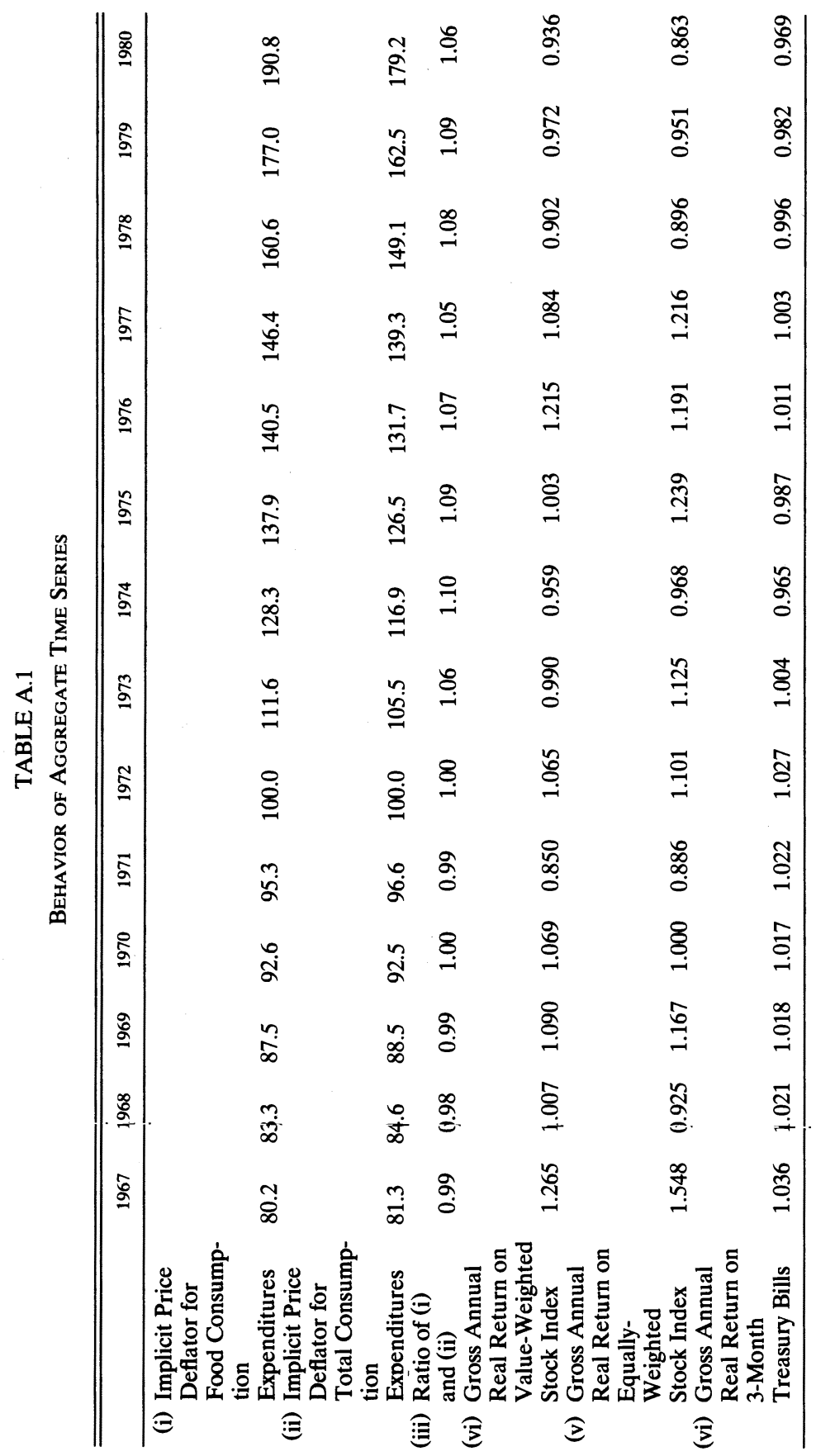


Reserve System publication, Federal Reserve Bulletin, various issues.) A geometrical average was used to derive the gross and annual return, i.e.

$$
\pi_{3 t}=\prod_{j=1}^{12}\left(1+R_{t j}\right)^{1 / 12} /\left(1+\pi_{t}\right)
$$

where $R_{t j}$ is the yearly nominal rate of return for year $t$, month $j$. The behavior of all the annual time series is displayed in Table A.1.

\section{REFERENCES}

Abramowitz, M., and I. Stegun, Eds. (1970): Handbook of Mathematical Functions. New York: Dover Publications.

AltoNJI, J. (1986): "Intertemporal Substitution in Labor Supply: Evidence from Micro Data," Journal of Political Economy, 94, S176-S215.

BECKER, G. (1965): "A Theory of the Allocation of Time," Economic Journal, 75, 493-517.

Bils, M. (1985): "Real Wages over the Business Cycle: Evidence from Panel Data," Joumal of Political Economy, 93, 666-689.

Board of Governors of the Federal Reserve System, Federal Reserve Bulletin, various issues.

Browning, M., A. Deaton, and M. IRISH (1985): "A Profitable Approach to Labor Supply and Commodity Demands over the Life-Cycle," Econometrica, 53, 503-543.

Chamberlain, G. (1984): "Panel Data," Chapter 22 in Handbook of Econometrics 2, Zvi Griliches and Michael Intriligator, eds. North Holland: Amsterdam and New York.

Chetty, V. (1968): "Pooling of Time Series and Cross Section Data," Econometrica, 36, 279-290.

Deaton, A. (1987): "Life-Cycle Models of Consumption: Is the Evidence Consistent with the Theory?" Chapter 14 in Advances in Econometrics - Fifth World Congress II, 121-148, ed. by T. Bewley. Cambridge: Cambridge University Press.

DunN, K., AND K. Singleton (1986): "Modeling the Term Structure of Interest Rates Under Non-separable Utility and Durability of Goods," Journal of Financial Economics, 17, 27-56.

Eichenbaum, M., L. Hansen, and K. Singleton (1988): "A Time Series Analysis of Representative Agent Models of Consumption and Leisure Choice under Uncertainty," Quarterly Journal of Economics, 103, 51-78.

Gallant, A., AND D. Jorgenson (1979): "Statistical Inference for a System of Simultaneous, Nonlinear, Implicit Equations in the Context of Instrumental Variable Estimation," Journal of Econometrics, 11, 272-302.

Ghez, G., AND G. Becker (1975): The Allocation of Time and Goods Over the Life Cycle. New York: NBER.

HALL, R. (1978): "Stochastic Implications of the Life Cycle-Permanent Income Hypothesis: Theory and Evidence," Journal of Political Economy, 86, 971-988.

HALl, R., AND F. MishKIN (1982): "The Sensitivity of Consumption to Transitory Income: Estimates from Panel Data on Households," Econometrica, 50, 461-482.

Hansen, L. (1982): "Large Sample Properties of Generalized Method of Moments Estimators," Econometrica, 50, 1029-1054.

HANSEN, L., AND K. Singleton (1982): "Generalized Instrumental Variables Estimation of Nonlinear Rational Expectations Models," Econometrica, 50, 1269-1286.

(1984): "Errata," Econometrica, 52, 267-268.

Hayashi, F. (1985): "The Permanent Income Hypothesis and Consumption Durability: Analysis Based on Japanese Panel Data," Quarterly Journal of Economics, 100, 1083-1113.

Heckman, J., and T. MaCurdy (1980): “A Life Cycle Model of Female Labour Supply," Review of Economic Studies, 47, 47-74.

- (1982): "Corrigendum on a Life Cycle Model of Female Labour Supply," Review of Economic Studies, 49, 659-660.

Heckman, J., ANd G. SedlaceK (1985): "Heterogeneity, Aggregation and Market Wage Functions: An Empirical Model of Self-Selection in The Labor Market," Journal of Political Economy, 93, $1077-1125$.

Hotz, V., F. Kydland, ANd G. SedlaceK (1988): "Intertemporal Preferences and Labor Supply," Econometrica, 56, 335-360.

Keane, M., R. MoffitT, AND D. Runkie (1988): "Real Wages over the Business Cycle: Estimating the Impact of Heterogeneity with Micro Data," Journal of Political Economy, 96, 1232-1266. 
Killingsworth, M. (1983): Labor Supply. Cambridge: Cambridge University Press.

MaCurdy, T. (1981): “An Empirical Model of Labor Supply in a Life-Cycle Setting," Joumal of Political Economy, 89, 1059-1085.

(1983): "A Simple Scheme for Estimating an Intertemporal Model of Labor Supply and Consumption in the Presence of Taxes and Uncertainty," International Economic Review, 24, 265-289.

- (1987): “A Framework for Relating Microeconomic and Macroeconomic Evidence on Intertemporal Substitution" Chapter 15 in Advances in Econometrics II, 149-176, ed. by T. Bewley. Cambridge: Cambridge University Press.

Mankiw, N., J. Rotemberg, and L. Summers (1985): "Intertemporal Substitution in Macroeconomics," Quarterly Journal of Economics, 100, 225-251.

Scheinkman, J. (1984): "General Equilibrium Models of Economic Fluctuations: A Survey of Theory," unpublished manuscript, University of Chicago.

SHAw, K. (1989): "Life-Cycle Labor Supply with Human Capital Accumulation," International Economic Review, 30, 431-456.

U.S. Department of Commerce, Bureau of Economic Analysis: National Income and Product Accounts of the U.S., 1929-1974.

- : Survey of Current Business. July 1977, July 1982.

Zellner, A. (1971): An Introduction to Bayesian Inference in Econometrics. New York: Wiley. 
http://www.jstor.org

\title{
LINKED CITATIONS
}

- Page 1 of 4 -

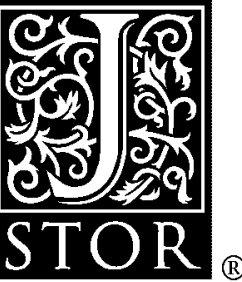

You have printed the following article:

\section{Household Choices in Equilibrium}

Sumru Altug; Robert A. Miller

Econometrica, Vol. 58, No. 3. (May, 1990), pp. 543-570.

Stable URL:

http://links.jstor.org/sici?sici=0012-9682\%28199005\%2958\%3A3\%3C543\%3AHCIE\%3E2.0.CO\%3B2-B

This article references the following linked citations. If you are trying to access articles from an off-campus location, you may be required to first logon via your library web site to access JSTOR. Please visit your library's website or contact a librarian to learn about options for remote access to JSTOR.

\section{References}

\author{
Intertemporal Substitution in Labor Supply: Evidence from Micro Data \\ Joseph G. Altonji \\ The Journal of Political Economy, Vol. 94, No. 3, Part 2: Hoover Institution Labor Conference. \\ (Jun., 1986), pp. S176-S215. \\ Stable URL: \\ http://links.jstor.org/sici?sici=0022-3808\%28198606\%2994\%3A3\%3CS176\%3AISILSE\%3E2.0.CO\%3B2-6
}

\author{
A Theory of the Allocation of Time \\ Gary S. Becker \\ The Economic Journal, Vol. 75, No. 299. (Sep., 1965), pp. 493-517. \\ Stable URL: \\ http://links.jstor.org/sici?sici=0013-0133\%28196509\%2975\%3A299\%3C493\%3AATOTAO\%3E2.0.CO\%3B2-N
}

\author{
Real Wages over the Business Cycle: Evidence from Panel Data \\ Mark J. Bils \\ The Journal of Political Economy, Vol. 93, No. 4. (Aug., 1985), pp. 666-689. \\ Stable URL: \\ http://links.jstor.org/sici?sici=0022-3808\%28198508\%2993\%3A4\%3C666\%3ARWOTBC\%3E2.0.CO\%3B2-K
}

\author{
A Profitable Approach to Labor Supply and Commodity Demands over the Life-Cycle \\ Martin Browning; Angus Deaton; Margaret Irish \\ Econometrica, Vol. 53, No. 3. (May, 1985), pp. 503-544. \\ Stable URL: \\ http://links.jstor.org/sici?sici=0012-9682\%28198505\%2953\%3A3\%3C503\%3AAPATLS\%3E2.0.CO\%3B2-P
}


http://www.jstor.org

\section{LINKED CITATIONS}

- Page 2 of 4 -

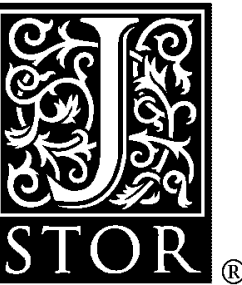

Pooling of Time Series and Cross Section Data

V. K. Chetty

Econometrica, Vol. 36, No. 2. (Apr., 1968), pp. 279-290.

Stable URL:

http://links.jstor.org/sici?sici=0012-9682\%28196804\%2936\%3A2\%3C279\%3APOTSAC\%3E2.0.CO\%3B2-W

A Time Series Analysis of Representative Agent Models of Consumption and Leisure Choice under Uncertainty

Martin S. Eichenbaum; Lars Peter Hansen; Kenneth J. Singleton

The Quarterly Journal of Economics, Vol. 103, No. 1. (Feb., 1988), pp. 51-78.

Stable URL:

http://links.jstor.org/sici?sici=0033-5533\%28198802\%29103\%3A1\%3C51\%3AATSAOR\%3E2.0.CO\%3B2-V

Stochastic Implications of the Life Cycle-Permanent Income Hypothesis: Theory and Evidence Robert E. Hall

The Journal of Political Economy, Vol. 86, No. 6. (Dec., 1978), pp. 971-987.

Stable URL:

http://links.jstor.org/sici?sici=0022-3808\%28197812\%2986\%3A6\%3C971\%3ASIOTLC\%3E2.0.CO\%3B2-K

The Sensitivity of Consumption to Transitory Income: Estimates from Panel Data on Households

Robert E. Hall; Frederic S. Mishkin

Econometrica, Vol. 50, No. 2. (Mar., 1982), pp. 461-481.

Stable URL:

http://links.jstor.org/sici?sici=0012-9682\%28198203\%2950\%3A2\%3C461\%3ATSOCTT\%3E2.0.CO\%3B2-R

\section{Large Sample Properties of Generalized Method of Moments Estimators}

Lars Peter Hansen

Econometrica, Vol. 50, No. 4. (Jul., 1982), pp. 1029-1054.

Stable URL:

http://links.jstor.org/sici?sici=0012-9682\%28198207\%2950\%3A4\%3C1029\%3ALSPOGM\%3E2.0.CO\%3B2-O

Generalized Instrumental Variables Estimation of Nonlinear Rational Expectations Models Lars Peter Hansen; Kenneth J. Singleton

Econometrica, Vol. 50, No. 5. (Sep., 1982), pp. 1269-1286.

Stable URL:

http://links.jstor.org/sici?sici=0012-9682\%28198209\%2950\%3A5\%3C1269\%3AGIVEON\%3E2.0.CO\%3B2-G 
http://www.jstor.org

\section{LINKED CITATIONS}

- Page 3 of 4 -

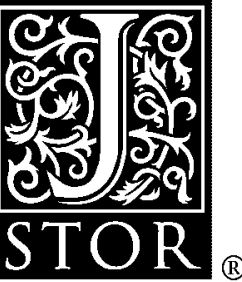

Generalized Instrumental Variables Estimation of Nonlinear Rational Expectations Models Lars Peter Hansen; Kenneth J. Singleton

Econometrica, Vol. 52, No. 1. (Jan., 1984), pp. 267-268.

Stable URL:

http://links.jstor.org/sici?sici=0012-9682\%28198401\%2952\%3A1\%3C267\%3AGIVEON\%3E2.0.CO\%3B2-1

The Permanent Income Hypothesis and Consumption Durability: Analysis Based on Japanese Panel Data

Fumio Hayashi

The Quarterly Journal of Economics, Vol. 100, No. 4. (Nov., 1985), pp. 1083-1113.

Stable URL:

http://links.jstor.org/sici?sici=0033-5533\%28198511\%29100\%3A4\%3C1083\%3ATPIHAC\%3E2.0.CO\%3B2-W

\section{A Life Cycle Model of Female Labour Supply}

James J. Heckman; Thomas E. Macurdy

The Review of Economic Studies, Vol. 47, No. 1, Econometrics Issue. (Jan., 1980), pp. 47-74.

Stable URL:

http://links.jstor.org/sici?sici=0034-6527\%28198001\%2947\%3A1\%3C47\%3AALCMOF\%3E2.0.CO\%3B2-\%23

\section{Corrigendum on A Life Cycle Model of Female Labour Supply}

James J. Heckman; Thomas MaCurdy

The Review of Economic Studies, Vol. 49, No. 4. (Oct., 1982), pp. 659-660.

Stable URL:

http://links.jstor.org/sici?sici=0034-6527\%28198210\%2949\%3A4\%3C659\%3ACOALCM\%3E2.0.CO\%3B2-F

Heterogeneity, Aggregation, and Market Wage Functions: An Empirical Model of Self-Selection in the Labor Market

James J. Heckman; Guilherme Sedlacek

The Journal of Political Economy, Vol. 93, No. 6. (Dec., 1985), pp. 1077-1125.

Stable URL:

http://links.jstor.org/sici?sici=0022-3808\%28198512\%2993\%3A6\%3C1077\%3AHAAMWF\%3E2.0.CO\%3B2-P

\section{Intertemporal Preferences and Labor Supply}

V. Joseph Hotz; Finn E. Kydland; Guilherme L. Sedlacek

Econometrica, Vol. 56, No. 2. (Mar., 1988), pp. 335-360.

Stable URL:

http://links.jstor.org/sici?sici=0012-9682\%28198803\%2956\%3A2\%3C335\%3AIPALS\%3E2.0.CO\%3B2-W 
http://www.jstor.org

\section{LINKED CITATIONS \\ - Page 4 of 4 -}

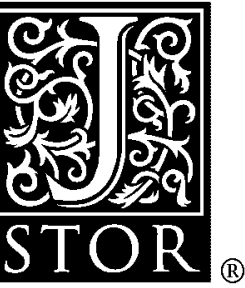

Real Wages over the Business Cycle: Estimating the Impact of Heterogeneity with Micro Data Michael Keane; Robert Moffitt; David Runkle

The Journal of Political Economy, Vol. 96, No. 6. (Dec., 1988), pp. 1232-1266.

Stable URL:

http://links.jstor.org/sici?sici=0022-3808\%28198812\%2996\%3A6\%3C1232\%3ARWOTBC\%3E2.0.CO\%3B2-L

\section{An Empirical Model of Labor Supply in a Life-Cycle Setting}

Thomas E. MaCurdy

The Journal of Political Economy, Vol. 89, No. 6. (Dec., 1981), pp. 1059-1085.

Stable URL:

http://links.jstor.org/sici?sici=0022-3808\%28198112\%2989\%3A6\%3C1059\%3AAEMOLS\%3E2.0.CO\%3B2-2

A Simple Scheme for Estimating an Intertemporal Model of Labor Supply and Consumption in the Presence of Taxes and Uncertainty

Thomas E. MaCurdy

International Economic Review, Vol. 24, No. 2. (Jun., 1983), pp. 265-289.

Stable URL:

http://links.jstor.org/sici?sici=0020-6598\%28198306\%2924\%3A2\%3C265\%3AASSFEA\%3E2.0.CO\%3B2-S

\section{Intertemporal Substitution in Macroeconomics}

N. Gregory Mankiw; Julio J. Rotemberg; Lawrence H. Summers

The Quarterly Journal of Economics, Vol. 100, No. 1. (Feb., 1985), pp. 225-251.

Stable URL:

http://links.jstor.org/sici?sici=0033-5533\%28198502\%29100\%3A1\%3C225\%3AISIM\%3E2.0.CO\%3B2-2

\section{Life-Cycle Labor Supply with Human Capital Accumulation}

Kathryn L. Shaw

International Economic Review, Vol. 30, No. 2. (May, 1989), pp. 431-456.

Stable URL:

http://links.jstor.org/sici?sici=0020-6598\%28198905\%2930\%3A2\%3C431\%3ALLSWHC\%3E2.0.CO\%3B2-C 